\title{
Investigative modeling of new pathways for secondary organic aerosol formation
}

\author{
B. K. Pun and C. Seigneur \\ Atmospheric and Environmental Research, Inc., 2682 Bishop Drive, Suite 120, San Ramon, CA 94583, USA
}

Received: 16 November 2006 - Published in Atmos. Chem. Phys. Discuss.: 10 January 2007

Revised: 15 March 2007 - Accepted: 16 April 2007 - Published: 3 May 2007

\begin{abstract}
Recent advances in secondary organic aerosol (SOA) research are reviewed and the status of current understanding is investigated using a box model of SOA formation. Benzene and isoprene are newly identified precursors that are included in this SOA model; these precursors form SOA via secondary products. The model is also extended to include some representation of aqueous partitioning and the formation of high molecular weight products via oligomerization. Experimental data and empirical relationships are used where possible, because a detailed representation of SOA formation is not supported by the current state of information. Sensitivity studies are conducted with the SOA model and SOA predictions are found to be very sensitive to the treatment of the interactions between particulate water and organic compounds. While uncertainties due to model formulation are significant, influential model parameters include the aerosol partitioning ratios for several small products of isoprene and the partitioning constants for unidentified products (currently, the partitioning constants are derived by fitting experimental data). The $\mathrm{pH}$ value used as the reference for the activation of oligomerization is also a critical parameter. Recommendations for future work needed to improve SOA models include the elucidation of the waterorganic relationship, the extent of phase separation, and laboratory experiments conducted under conditions more relevant to ambient studies (e.g., lower concentrations, higher relative humidity).
\end{abstract}

\section{Introduction}

Most three-dimensional air quality models use aerosol modules that are based on the state-of-the-science from the late 1990s, including the partition of anthropogenic and biogenic

Correspondence to: B. K. Pun

(pun@aer.com) secondary organic aerosols (SOA) based on empirical data from smog chambers (e.g., Odum et al., 1997; Griffin et al., 1999), with a correction factor applied to the equilibrium constant based on temperature (Strader et al., 1999; Pun et al., 2003). A few models have limited treatment of aqueous dissolution (e.g., Jacobson, 1997; Aumont et al., 2000; Pun et al., 2002; Griffin et al., 2003) or simple parameterizations of other processes (e.g., Morris et al., 2006). The early 2000s have seen several major advances in SOA research. Precursors have been identified that were previously believed not to lead to SOA formation, including benzene (Martin-Reviejo and Wirtz, 2005) and isoprene (Jang et al., 2002; Czoschke et al., 2003; Claeys et al., 2004a, b; Matsunaga et al., 2005). New processes have been identified that may lead to significant SOA formation, including oligomerization (Jang and Kamens, 2001; Jang et al., 2002; Czoschke et al., 2003; Limbeck et al., 2003; Gao et al., 2004b, Iinuma et al., 2004; Jang et al., 2005, 2006) and cloud processes (Warneck, 2003; Ervens et al., 2004a, b; Lim et al., 2005). In light of the poor model performance typical of PM models for organic aerosols (e.g., Seigneur and Moran, 2004), it is desirable to incorporate recent advances in SOA research into models to obtain an understanding of the impact of new pathways even though our theoretical understanding of many SOA forming processes is still incomplete. Such investigative modeling will allow us to identify the most uncertain parameters and processes and to recommend experiments needed to develop improved models of SOA formation.

In the current study, we focus on gas-phase, gas/particle partitioning and particulate-phase processes. Aqueous-phase reactions in clouds are not considered. An investigative SOA box model is formulated based on a synthesis of published information. This work is presented in three sections: the formulation of the box model; sensitivity analyses conducted with the model; and conclusions and recommendations for future work. The box model formulation includes new representations for the formation of SOA from isoprene and

Published by Copernicus GmbH on behalf of the European Geosciences Union. 
benzene and for the oligomerization of SOA species. Parameters for the formulations are derived in each case based on available laboratory and ambient measurements. The model formulations are tested against observations to gauge how well they reproduce SOA yields for isoprene and benzene and SOA enhancements due to oligomerization. Key assumptions and parameters used in the model formulations are then revisited in the sensitivity section. Sensitivity tests are conducted to understand the parameters (e.g., partitioning constants, observed aerosol partitioning ratios, fraction of SOA prone to oligomerization, $\mathrm{pH}$ required for oligomerization) and conditions (e.g., presence of particulate water) that influence SOA prediction. Based on these results, recommendations are made for additional information that will be the most useful to improve the formulation of more accurate SOA models.

\section{Model formulation}

\subsection{Benzene}

The yields of SOA from benzene range from 8 to $25 \%$ based on recent chamber data from Martin-Reviejo and Wirtz (2005). They found that the formation of SOA from benzene occurs only after the consumption of a threshold amount of benzene. Both the threshold and final SOA yield depend on $\mathrm{NO}_{\mathrm{x}}$ concentrations. The presence of $\mathrm{NO}_{\mathrm{x}}$ delayed SOA formation but enhanced the total amount formed. They also concluded that the formation of SOA does not occur as a first oxidation step, but as a result of the oxidation of secondary compounds, including ring-retaining products and ring-opening products. Because many uncertainties still exist in the reaction mechanism of benzene degradation, a semiempirical approach is, therefore, used here to incorporate the formation of SOA from benzene into models.

While there have been several attempts to develop detailed mechanisms for benzene degradation, condensed mechanisms are typically used in three-dimensional models of air quality. Such condensed mechanisms typically represent first reaction steps, generic secondary radicals, and lumped products. Here, we choose to start with a benzene reaction used in the Statewide Air Pollution Research Center (SAPRC) mechanism (Carter, 1990, 1996), as shown in Table 1. The three first-step oxidation products (besides peroxyl radicals) are phenol, glyoxal and a lumped species representing ringopening products. The stoichiometric coefficients of the reaction were determined based on model fits to environmental chamber data.

Phenol is an intermediate reactant that can lead to the formation of aromatic compounds with multiple substituents (e.g., nitrophenol, catechol) that may become SOA precursors. The reaction PHENOL + OH may be added to a mechanism that does not track PHENOL (OH may then be added as a product to retain the original chemical dynamics) or con- densable products may be added to an already existing reaction. We assume that the yield of SOA from phenol is analogous to the yield of SOA from toluene and other monosubstituted aromatic compounds based on Odum et al. (1997). Therefore, the reaction of PHENOL with $\mathrm{OH}$ forms the condensable compounds PHENAER1 and PHENAER2 (see Table 1 for stoichiometric coefficients). The partitioning coefficients of PHENAER1 and PHENAER2 are 0.053 and $0.0019 \mathrm{~m}^{3} / \mu \mathrm{g}$, respectively at $310 \mathrm{~K}$. Because the partitioning characteristics of PHENAER1 and PHENAER2 are the same as those of TOLAER1 and TOLAER2, the condensable products may be lumped in SOA modules based on Odum et al. (1997) with suitable corrections for the differences in molecular weight (MW).

Benzene is one of many sources of glyoxal. Anhydrous glyoxal has a vapor pressure of approximately 18 torr $(0.02 \mathrm{~atm})$ at $20^{\circ} \mathrm{C}$ (Hastings et al., 2005), and is, therefore, not very condensable. However, in chamber experiments, glyoxal condenses at low concentrations (Liggio et al., 2005; Hastings et al., 2005). The partitioning into an aqueous phase is enhanced by the formation of ethan-tetrol (glyoxal monomer dihydrate) and oligomers of the hydrate molecules. The effective Henry's law constant $\left(H_{\text {eff }}\right)$, i.e., the ratio of aqueous monomer and dihydrate concentrations to the gas-phase glyoxal concentration, is $3.6 \times 10^{5} \mathrm{M} / \mathrm{atm}$. The effective Henry's law constant leads to negligible particulate glyoxal in the ambient atmosphere. Oligomerization is expected to shift the effective partition behavior of glyoxal towards the particle phase (Jang et al., 2002; Liggio et al., 2005).

Glyoxal is also expected to participate in cloud processes (Lim et al., 2005) to give rise to oxalic acid, which can result in SOA formation if the cloud droplet evaporates to form a particle. This process needs to be incorporated in a cloud module and, therefore, is not represented here in the aerosol module.

For the partitioning of glyoxal, a formulation that represents the effective partitioning due to the hydrated form is used with a correction to the Henry's law formulation due to an acid-catalyzed oligomerization, which is discussed in Sect. 2.3. This formulation, therefore, requires the inputs of liquid water content (LWC), $\mathrm{RH}$, and $\mathrm{pH}$.

Koehler et al. (2004) suggested that furandione (a product of benzene oxidation with a gas-phase yield $\sim 4 \%$ ) can react with water to form dicarboxylic acid in the particulate phase. Acidity can subsequently increase the partitioning of aldehydes into the particulate phase, presumably due to enhanced oligomerization in the presence of acids. These processes are not represented here because of a lack of quantitative information.

As a group, ROP (ring-opening products) include many yet unidentified, multifunctional compounds. Some members of this group are aerosol precursors (e.g., muconaldehyde) and there is no a priori basis to define their partitioning characteristics or those of their products. To form 
Table 1. SOA-forming process for benzene.

\begin{tabular}{|c|c|c|}
\hline Type $^{a}$ & Reaction or equilibrium & Rate constant ${ }^{b}$ or equilibrium constant ${ }^{c}$ \\
\hline G & $\begin{array}{l}\text { BENZENE }+\mathrm{OH} \rightarrow 0.24 \mathrm{PHENOL}+ \\
0.21 \mathrm{GLYOXAL}+1.44 \mathrm{ROP}+0.24 \mathrm{HO}_{2}+ \\
0.76 \mathrm{RO}_{2}{ }^{\mathrm{d}}\end{array}$ & $2.5 \times 10^{-12} \exp (-0.397 / \mathrm{RT})$ \\
\hline G & $\begin{array}{l}\text { PHENOL }+ \text { OH } \rightarrow 0.071 \text { PHENAER } 1+ \\
0.138 \text { PHENAER } 2+\mathrm{OH}^{\mathrm{e}}\end{array}$ & $2.63 \times 10^{-11}$ \\
\hline $\mathrm{K}$ & PHENAER $1 \leftrightarrow$ APHENA1 & $0.053^{\mathrm{f}}$ \\
\hline $\mathrm{K}$ & PHENAER $2 \leftrightarrow$ APHENA2 & $0.0019^{f}$ \\
\hline $\mathrm{H}$ & GLYOXAL $\leftrightarrow$ AGLYO & $\begin{array}{l}0 \text { if } \mathrm{RH}<26 \% \\
3.6 \times 10^{5} \text { if } \mathrm{RH} \geq 26 \% \text { or } \mathrm{f}(\mathrm{pH})^{\mathrm{h}}\end{array}$ \\
\hline G & $\mathrm{ROP}+\mathrm{OH} \rightarrow$ ROPAER & $1.14 \times 10^{-11}$ \\
\hline K & ROPAER $\leftrightarrow$ AROPA & $0.0013^{\mathrm{i}}$ \\
\hline
\end{tabular}

a Type is either $G, K$, or $H . G$ is used for gas-phase reactions, $K$ is used for gas/particle equilibrium reactions, $H$ is used for gas/particle equilibrium reactions where the particulate phase is aqueous. ${ }^{b}$ Reaction rate constants are given in $\mathrm{cm}^{3} / \mathrm{molecule} / \mathrm{s}$. If the Arrhenius form is used, $R$ is $0.0019872 \mathrm{kcal} / \mathrm{deg} \mathrm{K} / \mathrm{mole}$. ${ }^{\mathrm{c}}$ Gas/particle equilibrium constants $(K)$ are given in $\mathrm{m}^{3} / \mu \mathrm{g}$. Henry's law constants (or effective Henry's law constants) are given in M/atm. ${ }^{\mathrm{d}} \mathrm{ROP}$ stands for ring-opening products. $\mathrm{RO}_{2}$ represents a generic peroxyl radical that reacts with $\mathrm{NO}$ to give $\mathrm{NO}_{2}$. ${ }^{\text {e }}$ The experimental mass-based stoichiometric factors are used as the molar stoichiometric coefficients, implicitly assuming that the PHENOL, PHENAER1, and PHENAER2 share the same molecular weight. The molar yield can be adjusted if the MW of the condensable products are assumed to be different from the MW of PHENOL. ${ }^{f}$ At $310 \mathrm{~K} .{ }^{\mathrm{g}}$ AGLYO stands for the aqueous forms of glyoxal including the glyoxal monomer dehydrate (ethan-tetrol). ${ }^{\mathrm{h}}$ Effective $H$ due to hydration; $H_{\mathrm{eff}}$ can be adjusted to account for oligomerization (e.g., as a function of $\mathrm{pH}$ ). ${ }^{\mathrm{i}}$ Determined based on experimental data and SOA model formulation, see text.

second-generation products, ROP are expected to react with OH (Carter et al., 1996). Partitioning characteristics of ROP are determined as described next so that $8-25 \%$ of the reacted benzene forms aerosols under dry conditions (MartinReviejo and Wirtz, 2005).

Four condensable products are assumed to be formed in the reactions of benzene (see Table 1): two secondgeneration products originating from the reactions of phenol, glyoxal, and a lumped second-generation product via ringopening reactions. In theory, a portion of the ROP products is expected to be condensable, characterized by some partitioning coefficient. Because of the uncertainties associated with the amount of ROP formed and subsequently reacted, a two-parameter characterization seems incompatible with available mechanistic data. One approach is to use a default stochiometric coefficient of 1 for a condensable product from ROP, and to derive a partitioning coefficient for this condensable product. The partitioning coefficient is treated as an adjustable parameter to achieve the experimental yields of $8-25 \%$. In this case, the experimental conditions of Martin-Reviejo and Wirtz (2005) were used. Glyoxal formation was considered to be negligible due to the use of low RH experimental conditions and the SOA mass was, therefore, assumed to consist of AROPA, APHENA1, and APHENA2. The yields of APHENA1 and APHENA2 were estimated for those experiments, assuming the reactions were complete when the maximum mass of particles was formed. First, the total amount of each condensable phenol product was estimated based on the amount of reacted benzene and the stoichiometry of phenol and PHENAER species, corrected for the difference in MW. Then, the amounts of particulate phase APHENA1 and APHENA2 were estimated based on the partitioning constant and the total amount of particulate matter (PM) present in the environmental chamber. The amount of AROPA was then estimated from the difference between the experimental SOA yield and the estimated yields of APHENA1 and APHENA2. The gas-phase concentration of ROPAER was calculated from the stoichiometry of the reaction and the amount of reacted benzene. For each experiment, the partitioning coefficient of ROPAER was then calculated using the ratio of mass fraction in the particulate phase to the gas-phase concentration. The average partitioning coefficient for ROPAER was calculated to be $0.0013 \mathrm{~m}^{3} / \mu \mathrm{g}$, with a range of 0.0008 to $0.0022 \mathrm{~m}^{3} / \mu \mathrm{g}$. When the model is used to simulate individual experiments in Martin-Reviejo and Wirtz (2005), it predicts SOA yields to range between $11 \%$ and $25 \%$ (vs. the observed range of $8 \%$ to $25 \%$ ). The average model bias is $+5 \%$, and the average model error is approximately $20 \%$.

\subsection{Isoprene}

The formation of SOA from isoprene is supported by both ambient observations as well as smog chamber and laboratory studies (Claeys et al., 2004a, b; Edney et al., 2005; Kroll et al., 2005a, 2006; Limbeck et al., 2003; Matsunaga et al., 2005). Several theories are available. The first one is the gas-phase formation of condensable compounds. Kroll et 
al. (2005a) reported 0.9 to $3.0 \%$ (by mass) yield of SOA from gas-phase reactions. Under their high- $\mathrm{NO}_{\mathrm{x}}$ experimental conditions, the $\mathrm{OH}+$ isoprene reaction was expected to dominate over the $\mathrm{O}_{3}+$ isoprene reaction. Oxidation reactions of isoprene products such as methacrolein, 3-methylfuran and other minor products are postulated to lead to SOA formation. Kroll et al. (2006) characterized SOA formation from isoprene under both high and low $\mathrm{NO}_{\mathrm{x}}$ conditions. The dependence of $\mathrm{SOA}$ on $\mathrm{NO}_{\mathrm{x}}$ concentrations implied different chemical mechanisms and products under different conditions. Low $\mathrm{NO}_{\mathrm{x}}$ experiments are expected to be more representative of the ambient atmosphere than high $\mathrm{NO}_{\mathrm{x}}$ experiments. Henze and Seinfeld (2006) parameterized the SOA yield from low $\mathrm{NO}_{\mathrm{x}}$ experiments using a two-product approach and applied the formulation in a global model.

Edney et al. (2005) found evidence for an $\mathrm{SO}_{2}$-assisted mechanism for SOA formation. Among SOA products, they found 2-methylglyceric acid and 2-methyl-butyl-1,2,3,4tetrols, and attributed the remaining SOA mass to oligomers. The same tracer products were identified by Surratt et al. (2006) under low $\mathrm{NO}_{\mathrm{x}}$ conditions. Claeys et al. (2004a, b) proposed mechanisms to form 2-methylglyceric acid and 2-methyl-butyl-1,2,3,4-tetrols from the reaction of isoprene. In their subsequent paper, they disputed the mechanism proposed in the original paper, which required gas-phase reactions under low $\mathrm{NO}_{\mathrm{x}}$ conditions. Their current theory involves the reaction of isoprene and methacrolein (a firstgeneration isoprene product) with $\mathrm{H}_{2} \mathrm{O}_{2}$ in acidic particles. (The authors contended that the lifetime of the reaction is inconsistent with the lifetimes of clouds.) The proposed reaction is analogous to the oxidation of $\mathrm{SO}_{2}$. Previous work has concluded that $\mathrm{SO}_{2}$ oxidation occurs mostly in cloud droplets because the same reactions in aqueous particles cannot be significant due to the very low liquid water volume available for reaction (Saxena and Seigneur, 1987; Meng and Seinfeld, 1994). Since isoprene is less soluble than $\mathrm{SO}_{2}$, the reaction in aqueous particles cannot account for the di- and tetra-hydroxy products and such reactions are more likely to occur in clouds. As mentioned above, we do not attempt here to represent cloud reactions.

Surratt et al. (2006) confirmed that organic peroxides are key gas-phase reaction products under low $\mathrm{NO}_{\mathrm{x}}$ conditions. Both Kroll et al. (2006) and Surratt et al. (2006) expected organic peroxides to undergo further reactions in the atmosphere.

High MW products or oligomers are formed from isoprene in the presence of acid catalysts (Czoschke et al., 2003; Limbeck et al., 2003). With ammonium sulfate seeds, Kroll et al. (2005a) found no evidence of high MW products. However, subsequent experiments by Kroll et al. (2006) and Dommen et al. (2006) found high MW products under both high and low $\mathrm{NO}_{\mathrm{x}}$ conditions. Surratt et al. (2006) identified acidic oligomers under high $\mathrm{NO}_{\mathrm{x}}$ conditions and neutral oligomers under low $\mathrm{NO}_{\mathrm{x}}$ conditions among the SOA products of isoprene.
Matsunaga et al. (2005) found that in the ambient atmosphere, small multifunctional compounds, such as glycolaldehyde (GLYALD), hydroxyacetone (HYACET), and methylglyoxal (MGLY), show much higher affinity towards the particle phase than predicted based on their Henry's law constants. The observed aerosol partition ratio (APR; the dimensionless ratio of the particulate-phase concentration over the total [gas + particulate] concentration) correlates linearly with $\mathrm{RH}$, and the authors proposed oligomerization as a possible reason.

Another mechanism that has been explored involves aqueous reactions in clouds (e.g., Lim et al., 2005; Ervens et al., 2004a, b; Warneck, 2003). As mentioned above, our focus here is to investigate aerosol processes; cloud processes are discussed extensively in the publications referenced above.

The exact mechanism for SOA formation from isoprene has not been elucidated, and factors affecting each potential process, e.g., competing oxidants, $\mathrm{NO}, \mathrm{RH}$, to name a few, are still being studied. At this time, we use two different algorithms for modeling isoprene SOA to represent different SOA species implicated in an ambient experiment (Matsunaga et al., 2005) and laboratory experiments (Henze and Seinfeld, 2006 and Kroll et al., 2006). The first approach uses specific organic compounds for SOA formation whereas the second approach uses two surrogate compounds to fit the smog chamber experimental results. Both approaches are represented in Table 2. Differences in SOA predictions from these two algorithms represent uncertainties due to different model formulation approaches.

To formulate a modeling approach based on the ambient data of Matsunaga et al., we start with the gas-phase reactions for isoprene from the SAPRC mechanism (Carter and Atkinson, 1996), although similar gas-phase reactions are available in many common mechanisms. The main gasphase products, methacrolein (MACR) and methylvinylketone (MVK), are tracked specifically, but other products are lumped into unidentified isoprene products (ISOPRD). The SAPRC mechanism accounts for the fate of the isoprene products relating to $\mathrm{O}_{3}$ production. Here, we focus only on second-generation products leading to the formation of SOA.

Matsunaga et al. (2005) expected the partitioning of GLYALD, HYACET, and MGLY to be a function of RH. Based on ambient observations, they reported a linear fit of the APR as a function of $\mathrm{RH}$, but the coefficients of determination were low $\left(r^{2}=0.4,0.2\right.$, and 0.2 for three compounds) due to significant scatter of the data. GLYALD, HYACET, and MGLY are small compounds with two hydrophilic functional groups, some of which interact with protons. At any given RH, ambient particles can be associated with different amounts of water and proton concentrations due to differences in inorganic and organic PM composition. Such differences can account for the range of partitioning characteristics. An inspection of the raw data reveals that the RH effect may be modeled more appropriately in terms of ranges of separate values of APR for specific ranges of RH, as shown 
Table 2a. SOA-forming process for isoprene using the data from Matsunaga et al. (2005).

\begin{tabular}{|c|c|c|}
\hline Type $^{\mathrm{a}}$ & Reaction or equilibrium & $\begin{array}{l}\text { Rate constant }{ }^{\mathrm{b}} \text {, equilibrium } \text { constant }^{\mathrm{c}} \text { or } \\
\text { aerosol partitioning ratio }\end{array}$ \\
\hline G & $\begin{array}{l}\text { ISOPRENE }+ \text { OH } \rightarrow 0.91 \mathrm{RO} 2+0.09 \mathrm{RNO} 3+0.62 \\
\mathrm{HCHO}+0.23 \mathrm{MACR}+0.32 \mathrm{MVK}+ \\
0.36 \mathrm{ISOPRD}^{\mathrm{e}}\end{array}$ & $2.5 \times 10^{-11} \exp (408 / \mathrm{T})$ \\
\hline G & $\begin{array}{l}\text { ISOPRENE }+\mathrm{O}_{3} \rightarrow 0.27 \mathrm{OH}+0.066 \mathrm{RO}_{2}+0.008 \\
\mathrm{RNO}_{3}+0.59 \mathrm{HCHO}+0.1 \mathrm{ISOPRD}+0.39 \mathrm{MACR}+ \\
0.16 \mathrm{MVK}+0.2 \mathrm{HCOOH}+ \\
0.15 \mathrm{RCOOH}^{\mathrm{e}}\end{array}$ & $7.86 \times 10^{-15} \exp (-1912 / \mathrm{T})$ \\
\hline G & $\begin{array}{l}\text { ISOPRENE }+\mathrm{NO}_{3} \rightarrow 0.19 \mathrm{NO}_{2}+0.75 \mathrm{RO}_{2}+0.064 \\
\mathrm{RNO}_{3}+0.94 \mathrm{ISOPRD}^{\mathrm{e}}\end{array}$ & $3.03 \times 10^{-12} \exp (-448 / \mathrm{T})$ \\
\hline G & $\mathrm{MVK}+\mathrm{OH} \rightarrow 0.7 \mathrm{GLYALD}+0.3 \mathrm{MGLY}^{\mathrm{e}}$ & $4.14 \times 10^{-12} \exp (453 / \mathrm{T})$ \\
\hline G & $\begin{array}{l}\text { MACR + OH } \rightarrow 0.42 \text { HYACET }+ \\
0.08 \mathrm{MGLY}^{\mathrm{e}}\end{array}$ & $1.86 \times 10^{-11} \exp (176 / \mathrm{T})$ \\
\hline $\mathrm{H}$ & MGLY $\leftrightarrow$ AMGLY & $\begin{array}{l}0.21 \text { if } \mathrm{RH}<60 \% \\
0.25 \text { if } \mathrm{RH} \geq 60 \% \mathrm{~d}\end{array}$ \\
\hline $\mathrm{H}$ & HYACET $\leftrightarrow$ AHYACET & $\begin{array}{l}0.24 \text { if } \mathrm{RH}<60 \% \\
0.36 \text { if } \mathrm{RH} \geq 60 \% \mathrm{~d}\end{array}$ \\
\hline $\mathrm{H}$ & GLYALD $\leftrightarrow$ AGLYALD & $\begin{array}{l}0.10 \text { if } \mathrm{RH}<60 \% \\
0.36 \text { if } \mathrm{RH} \geq 60 \% \mathrm{~d}\end{array}$ \\
\hline
\end{tabular}

Table 2b. SOA-forming process for isoprene using the smog chamber data of Kroll et al. (2006) as analyzed by Henze and Seinfeld (2006).

\begin{tabular}{lll}
\hline Type $^{\text {a }}$ & Reaction or equilibrium & $\begin{array}{l}\text { Rate constant } \\
\text { aerosol partitioning ratio }\end{array}$ \\
\hline $\mathrm{G}$ & ISOPRENE $+\mathrm{OH} \rightarrow 0.91 \mathrm{RO}_{2}+0.09 \mathrm{RNO}_{3}+0.62$ & $2.5 \times 10^{-11} \exp (408 / \mathrm{T})$ \\
& $\mathrm{HCHO}+0.23 \mathrm{MACR}+0.32 \mathrm{MVK}+0.36$ ISOPRD + & \\
& $0.232^{\mathrm{f}}$ ISOAER1 + 0.0288 ISOAER2 $^{\mathrm{f}}$ & $0.00862^{\mathrm{f}}$ \\
$\mathrm{K}$ & ISOAER $1 \leftrightarrow$ AISOA 1 & $1.62^{\mathrm{f}}$ \\
$\mathrm{K}$ & ISOAER2 $\leftrightarrow$ AISOA2 & or $^{\mathrm{f}}$ \\
\hline
\end{tabular}

${ }^{\mathrm{a}-\mathrm{c}}$ see notes for Table 1. ${ }^{\mathrm{d}}$ aerosol partitioning ratio $(\mathrm{P} /(\mathrm{G}+\mathrm{P})$ - observation based, representing effective partitioning (including effects of oligomerization); values represent the median observed value at each RH range (raw APR data from Matsunaga, private communication, 2006); ${ }^{\mathrm{e}} \mathrm{RNO}_{3}$ stands for alkyl nitrates; HCHO is formaldehyde; MACR is methacrolein; MVK is methyl vinyl ketone; ISOPRD is other isoprene products, ISOAER1 and ISOAER2 are condensable isoprene products (Henze and Seinfeld, 2006 formulation); HCOOH is formic acid; RCOOH is acetic acid; GLYALD is glycolaldehyde; HYACET is hydroxyacetone; MGLY is methylglyoxal; ${ }^{\mathrm{f}}$ Henze and Seinfeld (2006).

in Table 2a, rather than with a weak linear correlation between APR and RH.

Of the first-generation isoprene products, Kroll et al. (2005b) did not find evidence for the uptake of MGLY and other simple carbonyls on neutral or acidic seed particles. Zhao et al. (2006) found heterogeneous reactions of MGLY to decrease with acidity. Discrepancies between these studies regarding MGLY uptake remain to be resolved. Nevertheless, a model formulation for MGLY based on acid-catalyzed oligomerization is not supported by current evidence (Kroll et al., 2005b; Zhao et al., 2006).
Environmental chamber experiments are typically conducted at relative humidity below $60 \%$ (e.g., Kroll et al., 2006; Dommen et al., 2006). The APR approach results in a maximum SOA yield of $7 \%$ for isoprene when RH is below $60 \%$. This value is slightly higher than but not inconsistent with the ranges of SOA yields of 0.9 to $5.5 \%$ reported by Kroll et al. (2006) and 0.2 to $5.3 \%$ reported by Dommen et al. (2006).

Henze and Seinfeld (2006), based on data from Kroll et al. (2006), proposed an absorption model involving two surrogate products to represent the formation of SOA from isoprene under low $\mathrm{NO}_{\mathrm{x}}$ conditions. The two product model for 
the overall SOA yield is implemented as the first-generation of a semivolatile product followed by a condensation step. Kroll et al. (2006) postulated that organic peroxides constitute key components of isoprene SOA. This is supported by the product study of Surratt et al. (2006), which also identified other multifunctional products, including those in Claeys et al. (2005) and oligomeric products. Second-generation products, and further reactions in the particulate phase are implicitly represented by the parameter fits (Kroll and Seinfeld, 2005). Therefore, this approach (Table 2b) represents an alternative formulation of SOA from isoprene to that based on GLYALD, HYACET, and MGLY (Matsunaga et al., 2005).

\subsection{Oligomerization}

\subsubsection{Partitioning module formulation}

The term oligomerization is used here to describe a range of processes that form high MW compounds. To date, several reactions have been postulated to contribute to the formation of high MW species in SOA, including hemiacetal and acetal formation, trioxane formation, polymerization, aldol condensation (Jang et al., 2003, 2005), and peroxyhemiacetals (Johnson et al., 2005; Docherty et al., 2005). However, the precursors and oxidants involved, condensing species that are subject to oligomerization, and the environmental conditions favorable for such reactions remain poorly characterized. It is possible that multiple processes, including ones not yet identified, are involved in the formation of high MW compounds in the ambient atmosphere. A few studies have attempted to account for association reactions by assuming stable, nonvolatile products that increase SOA mass via irreversible reactions (e.g., Johnson et al., 2005). This assumption may be an oversimplication because (1) current laboratory data support a hypothesis that such products may decompose back to precursor species (e.g., Hastings et al., 2005; Ziemann, 2005) (hence they may not be detectable in routine experiments) and (2) some theoretical calculations show that the high MW products formed are not always thermodynamically favored over the lower MW reactants (Barsanti and Pankow, 2004, 2005).

Kroll and Seinfeld (2005) show that if a partitioning compound reacts further in the particulate phase, then as long as the final product is less volatile than the partitioning species, an apparent partitioning constant can be used to describe the system to account for the abundance of SOA due to the particulate phase reaction. In this case, the apparent or effective partitioning constant $\left(K_{p \text {,eff }}\right)$ equals $K_{p}\left(1+K_{\mathrm{rxn}}\right)$, where $K_{p}$ is the gas-particle partitioning constant and $K_{\mathrm{rxn}}$ is the first-order equilibrium constant of the particulate phase reaction. Such a formulation seems appropriate to represent SOA oligomerization, and a first-order equilibrium constant is derived below for the oligomerization reaction.
One school of thought involves acid-catalyzed association or oligomerization reactions (Gao et al., 2004; Jang et al., 2005). Aldehyde moieties have been found to be more reactive than ketones (Jang et al., 2003, 2005) in acidcatalyzed association reactions. (Double bonds are also postulated to be a candidate reactant for oligomerization; Limbeck et al., 2003.) In this case, the monomers are SOA with hydrated carbonyl groups. Jang et al. (2005) derived a semi-empirical yield expression for oligomeric products based on the dimerization reaction. Although the formation of dimers is a second-order process under experimental conditions, a pseudo-first-order formulation can be used under atmospheric conditions. Each monomer can react with a pool of other monomers, and the assumption is that the total concentration of the monomers stays relatively constant. We reformulate the yield of Jang et al. (2005) using a pseudofirst-order approach, and derive a first-order equilibrium constant for the particle-phase reaction converting monomers to oligomers. This first-order equilibrium constant depends on $\mathrm{pH}$ according to the semi-empirical derivation of Jang et al. (2005). A reference state is defined where some small amount of oligomers is formed without added protons to catalyze the reactions (Gao et al., 2004). The equilibrium constants at different $\mathrm{pH}$ are calculated relative to that reference state and then applied as a correction to the gas-particle partitioning constant to account for further particulate-phase transformations based on Kroll and Seinfeld (2005).

The model system of Jang et al. (2005) is based on an aldehyde hydrate undergoing polymerization, but can be generalized to a variety of acid-catalyzed reactions. In that formulation (M. Jang, personal communication, 2006), the socalled "second-order relative organic aerosol yield" $(Y)$ (proportional to a mass fraction equilibrium relationship) is defined as

$Y=\frac{10^{-3} \mathrm{MW}_{i} \cdot O M}{M_{\text {seed }}\left(K_{p} C_{\text {init }}\right)^{2}}$

where $\mathrm{MW}_{i}$ is the $\mathrm{MW}$ of the monomer compound $i, \mathrm{OM}$ represents the mass $\left(\mathrm{mg} / \mathrm{m}^{3}\right.$ air $)$ of the higher MW compounds, $M_{\text {seed }}\left(\mathrm{mg} / \mathrm{m}^{3}\right.$ air $)$ is the concentration of initial particulate matter (seed) in the experiment, $K_{p}$ is the equilibrium partitioning coefficient of the monomer between the gas and particulate phases and $C_{\text {init }}$ is the initial concentration of the monomer in the gas phase $\left(\mathrm{mg} / \mathrm{m}^{3}\right.$ air). The term $K_{p} * C_{\text {init }}$ represents the monomer mass fraction in the particulate phase that is in equilibrium with the gas phase under experimental conditions. Therefore, $Y$ is second order with respect to the monomer mass fraction. This yield is proportional to the second-order partitioning coefficient assuming the self reaction of $i$ in the particulate phase:

Monomer + Monomer $\leftrightarrow$ High MW Product (oligomer)

$K_{e q}=\frac{\left[\text { oligomer }_{i}\right]}{\left[\text { monomer }_{i}\right]^{2}}$ 
where $[x]$ represents the particulate phase concentration (mole/L) of $x$. To account for ambient conditions rather than experimental conditions, we calculate the "second-order relative organic aerosol yield" $Y$ where $M_{\mathrm{AOM}}$ replaces $M_{\text {seed }}$ as the absorbing medium, and $C_{g, i}$ (gas-phase concentrations) replaces $C_{\text {init }}$ (initial concentrations). Under experimental conditions, seed aerosols are controlled; however, in the ambient atmosphere, monomer condensation and oligomer production can take place in a mixture of primary (inorganic or organic) and secondary compounds. Thus, the change in representation from seed mass to absorbing medium mass represents an uncertainty due to extrapolating a laboratory model formulation to ambient conditions. Note that for ambient concentrations, $\mu \mathrm{g} / \mathrm{m}^{3}$ is the more appropriate concentration units compared to $\mathrm{mg} / \mathrm{m}^{3}$. The yield in the ambient atmosphere, $Y_{a}$, is then expressed as follows:

$Y_{a}=\frac{10^{-3} \mathrm{MW}_{i} \cdot \mathrm{OM}}{M_{\mathrm{AOM}}\left(K_{p} C_{g, i}\right)^{2}}$

The monomer mass fraction in the particulate phase is equal to $K_{p} C_{g, i}$. In the ambient atmosphere, self reactions are less likely because a mixture of condensable species is present. Therefore, we define an analogous equilibrium relationship for a monomer reacting with a pool of other monomers (assumed to be constant), such that a first order "effective" equilibrium coefficient can be defined to be proportional to $Y_{a}$.

$$
\begin{aligned}
& K_{o, i}=\frac{\left[\text { oligomer }_{i}\right]}{\left[\text { monomer }_{i}\right] \cdot \sum_{j}\left[\text { monomer }_{j}\right]} \\
& \frac{\left[\text { oligomer }_{i}\right]}{\left[\text { monomer }_{i}\right]}=K_{o, i} \sum_{j}\left[\text { monomer }_{j}\right]=K_{o, \text { eff }, i}
\end{aligned}
$$

where $K_{o, i}$ is the equilibrium constant for the formation of higher MW product from monomer $i, C_{\text {monomer, } i}$ is the concentration of monomer $i$ in the particulate phase, $\sum_{j}$ monomer $_{j}$ is the total concentration of all monomer species that can participate in the oligomerization reaction (e.g., all compounds containing the aldehyde functional group) and $K_{o, \text { eff, } i}$ is a first-order effective equilibrium constant for the formation of higher MW products from monomer $i$. We assume that, since $K_{o, i}$ is proportional to $Y$, it has the same parametric dependence as $Y$ in Jang et al. (2005).

$Y$ was found to depend on several parameters, including the excess acidity $(X), \mathrm{pH}$, the basicity constant of the monomer species (i.e., the equilibrium constant for the protonated form of the isomer, $K_{\mathrm{BH}+}$ ), and the hydration constant (i.e., the equilibrium constant for the hydrated form of the monomer). Of these parameters, the hydration constant depends on the structure of the reacting compounds and is assumed to be constant for a given class of compounds. For the compounds tested in Jang et al. (2005), aldehydes were about two orders of magnitude more reactive towards oligomerization than ketones. Therefore, as a first approximation, only aldehyde groups are assumed to participate in oligomerization reactions. The empirical model of Jang et al. (2005) is simplified to:

$$
\log Y=x X+z Z+r \log \left(K_{\mathrm{BH}+}\right)+11.79
$$

where $Z$ is the $\mathrm{pH}$ function $\left(Z=\log \left(C_{\mathrm{H}+} a_{w}\right)\right.$, where $C_{\mathrm{H}+}$ is the proton concentration (mole/L) and $a_{w}$ is the water activity $(=\mathrm{RH})) . X$ is a function of proton concentrations and activity coefficients of the species involved in the protonation reaction of carbonyl functional group; $X$ was also found to be strongly correlated to RH. The hydration constant for aldehyde species is already taken into account in the intercept term. For example, conjugation with a double bond was found to increase the stability of the protonated form. At this point, detailed molecular structure information is not available to support the model representation of SOA species beyond surrogate structures. Therefore, a constant value was assumed for $K_{\mathrm{BH}+}$ for all aldehyde-containing species. Jang et al. (2005) also found that two of the parameters, $X$ and $Z$, are strongly negatively correlated. Since $X$ is supposed to increase linearly with RH $(X=0.0372(\% \mathrm{RH})-3.716)$ (Jang et al., 2003) and $a_{w}$ is by definition equal to RH, the negative correlation indicates the overwhelming driving force associated with the concentration of protons. Although the presence of some water is necessary for the presence of protons, water dilutes the concentration of SOA and may slow down oligomerization when present in high concentration. There is, at present, no information on how much water is necessary to trigger oligomerization reactions. Using a theoretical approach, Pun et al. (2005) showed that SOA formed from common anthropogenic and biogenic precursors may be associated with up to $5 \mu \mathrm{g} / \mathrm{m}^{3}$ of water, depending on RH and the characteristics of SOA. A relative oligomerization yield can be defined using a simple relationship with the concentration of protons.

$$
\log \left(Y / Y_{\text {ref }}\right)=z \log \left(C_{\mathrm{H}+} / C_{\mathrm{H}+, \text { ref }}\right)
$$

where $z=1.91$ based on Jang et al. (2005). We further assume that the ratio of the effective first-order equilibrium constants (monomer + all aldehydes) is the same as the ratio of the second-order equilibrium constants. Therefore, for species $i$,

$\log \left(\frac{K_{o, i}}{K_{o, i, \text { ref }}}\right)=\log \left(\frac{Y_{i}}{Y_{i, \text { ref }}}\right)=z \log \left(\frac{C_{\mathrm{H}+}}{C_{\mathrm{H}+, \text { ref }}}\right)$

If we assume that the equilibrium aldehyde monomer concentration does not change with $\mathrm{pH}$ (i.e., only the concentration of the protonated monomer does), then the ratio of $K_{o, \text { eff }, i}$ will be the same as the ratio of $K_{o, i}$. 
Table 3. Aerosol-forming reactions for surrogate precursor compounds (only SOA products are listed).

\begin{tabular}{|c|c|c|}
\hline $\begin{array}{l}\text { Precursor compound } \\
\text { (molecular weight) }\end{array}$ & Gas-Phase Reactions $^{\mathrm{a}}$ & $\begin{array}{l}\text { Rate constants } \\
\left(\mathrm{cm}^{3} \text { molec }^{-1} \mathrm{~s}^{-1}\right)^{\mathrm{b}}\end{array}$ \\
\hline $\begin{array}{l}\text { Toluene and other high } \\
\text { SOA yield aromatics (92) }\end{array}$ & $\begin{array}{l}\mathrm{TOL}+\mathrm{OH} \rightarrow 0.118 \mathrm{GLYOXAL}+0.131 \mathrm{MGLY}+0.033 \mathrm{TO}- \\
\mathrm{LAER} 1+0.0830 \mathrm{TOLAER} 2^{\mathrm{c}, \mathrm{d}}\end{array}$ & $1.81 \times 10^{-12} \exp (-0.397 / \mathrm{RT})$ \\
\hline $\begin{array}{l}\text { Xylene and other low SOA } \\
\text { yield aromatics (106) }\end{array}$ & $\begin{array}{l}\text { XYL }+\mathrm{OH} \rightarrow 0.108 \text { GLYOXAL }+0.370 \text { MGLY }+0.023 \\
\text { XYLAER } 1+0.046 \text { XYLAER } 2+0.070 \text { XYLAERO2 } 2^{c, d}\end{array}$ & $1.73 \times 10^{-12} \exp (0.705 / \mathrm{RT})$ \\
\hline Humulene (206) & $\mathrm{HUM}+\mathrm{OH} \rightarrow 0.847$ HUMAERO & $2.93 \times 10^{-10}$ \\
\hline Limonene (136) & $\begin{array}{l}\mathrm{LIM}+\mathrm{OH} \rightarrow 0.168 \text { LIMAER } 1+0.039 \text { LIMAER } 2+0.251 \\
\text { LIMAERO2 }\end{array}$ & $1.71 \times 10^{-10}$ \\
\hline$\alpha$-Pinene (136) & $\begin{array}{l}\text { APIN }+ \text { OH } \rightarrow 0.028 \text { APINAER } 1+0.061 \text { APINAER } 2+ \\
0.199 \text { APINAERO } 2 \\
\text { APIN }+ \text { O3 } \rightarrow 0.089 \text { APINAER } 3+0.033 \text { APINAER } 4+ \\
0.046 \text { APINAERO4 }\end{array}$ & $\begin{array}{l}5.37 \times 10^{-11} \\
8.66 \times 10^{-17}\end{array}$ \\
\hline$\beta$-Pinene (136) & $\begin{array}{l}\text { BPIN }+ \text { OH } \rightarrow 0.092 \text { BPINAER } 1+0.038 \text { BPINAER2 } \\
\text { BPIN }+ \text { O3 } \rightarrow 0.019 \text { BPINAER } 3+0.423 \text { BPINAER } 4+0.032 \\
\text { BPINAERO4 } \\
\text { BPIN + NO3 } \rightarrow 0.739 \text { BPINAER5 }\end{array}$ & $\begin{array}{l}7.89 \times 10^{-11} \\
1.36 \times 10^{-17} \\
2.31 \times 10^{-12}\end{array}$ \\
\hline Terpinene (136) & $\mathrm{TER}+\mathrm{OH} \rightarrow 0.058 \mathrm{TERAER} 1+0.397 \mathrm{TERAERO} 2$ & $2.7 \times 10^{-10}$ \\
\hline Terpinenol (154) & $\mathrm{TPO}+\mathrm{OH} \rightarrow 0.035 \mathrm{TPOAER} 1+0.052 \mathrm{TPOAERO} 2$ & $1.59 \times 10^{-10}$ \\
\hline
\end{tabular}

a Notation for SOA products is xxxAERn or xxxAEROn where $\mathrm{xxx}$ is the precursor, $n$ is an integer, AER represents products that do not undergo oligmerization, and AERO represents SOA products subject to oligomerization ${ }^{\mathrm{b}} R$ is $0.0019872 \mathrm{kcal} / \mathrm{deg} \mathrm{K} / \mathrm{mol} ; k$ from Carter (1990) for toluene and xylene and from Pun et al. (2003) and references therein for biogenic compounds. ${ }^{\mathrm{c}}$ yields of GLYOXAL and MGLY are from Carter, 1990. ${ }^{\mathrm{d}}$ although cresol, a gas-phase product can probably lead to the formation of SOA, in a manner analogous to phenol (see Table 1), cresol products are probably already accounted for in TOLAER1 and TOLAER2.

$$
\begin{aligned}
\log \left(\frac{K_{o, \text { eff }, i}}{K_{o, \text { eff }, i, \text { ref }}}\right) & =\log \left(\frac{K_{o, i} \cdot \sum_{j}\left[\text { monomer }_{j}\right]}{K_{o, i, \text { ref }} \cdot \sum_{j}\left[\text { monomer }_{j}\right]_{\text {ref }}}\right) \\
& =\log \left(\frac{K_{o, i}}{K_{o, i, \text { ref }}}\right)
\end{aligned}
$$

The definition of $K_{o \text {, eff, } i \text {, ref }}$ and $C_{\mathrm{H}+\text {,ref }}$ is problematic, because the experiments carried out to date have typically been designed to maximize the formation of oligomers via the use of acidic seeds, high concentrations of reactants, or the addition of co-reactants that enhance the formation of oligomers. Gao et al. (2004) used several experimental conditions involving acidic and non-acidic seed particles. They estimated the mass fraction of oligomers to be at least $10 \%$, with the lower end value associated with a concentration of $\mathrm{H}^{+}$due to the intrinsic production of organic acids from the reaction system producing SOA. Therefore, we use a reference value

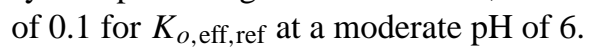

A module for simulating SOA needs to be computationally efficient if it is to be used for three-dimensional applications. Accordingly, most SOA models employ a surrogate representation or a hybrid one with surrogates and explicit species. For organic precursors, hundreds of SOA products can be formed and a surrogate representation is almost nec- essary for a majority of the products. As a starting point, the aerosol yield data from Odum et al. (1997) and Griffin et al. (1999) are used (e.g., Zhang et al., 2004). In that formulation, each precursor compound is associated with one or two surrogate products. The SOA yield of each surrogate product depends on two parameters, one representing the mass-based stoichiometric coefficient $(\alpha)$ and one representing a partitioning coefficient $\left(K_{p}\right) . K_{p}$ is corrected for temperature using the Clausius-Clapeyron equation assuming an enthalpy of vaporization of $72.7 \mathrm{~kJ} / \mathrm{mol}$ (Pun et al., 2003). Because oligomerization is typically catalyzed by protons, interaction with water is implicitly assumed. The inclusion of water in the absorbing medium necessitates another correction of $K_{p}$ based on the MW (Pankow, 1994). In the dry chamber experiments, the empirical $K_{p}$ reflects the absorption into an SOA phase. With water interaction, the MW of the absorbing medium will typically decrease, hence increasing the value of $K_{p}$.

Smog chamber experiments described in Odum et al. (1997) and Griffin et al. (1999) were conducted in relatively dry conditions that are not conducive to oligomerization. We assume that the experimental "effective" $K_{p}$ values represent a situation where the condensed mixture contains mostly monomers, with a minimal amount (10\%) of oligomers. When polymerization takes place, $\alpha$ does not change, but the effective $K_{p}$ increases. 
Table 4. Aerosol-forming equilibria for SOA compounds produced by surrogate precursors*.

\begin{tabular}{|c|c|c|c|}
\hline SOA (molecular weight) & Equilibrum Type $^{\mathrm{a}}$ & Equilibrium & Equilibrum constant @ $298 \mathrm{~K}$ \\
\hline GLYOXAL (58) & $H$ & GLYOXAL $\leftrightarrow$ AGLYO & see Table 1 \\
\hline MGLY (72) & $H$ & MGLY $\leftrightarrow$ AMGLY & see Table 2 \\
\hline TOLAER1 (198) & $K$ & TOLAER $1 \leftrightarrow$ ATOLA1 & 0.16 \\
\hline TOLAER2 (153) & K & TOLAER2 $\leftrightarrow$ ATOLA2 & 0.0057 \\
\hline XYLAER1 (175) & $K$ & XYLAER $1 \leftrightarrow$ AXYLA1 & 0.13 \\
\hline XYLAER2 (152) & K & XYLAER2 $\leftrightarrow$ AXYLA2 & 0.0042 \\
\hline XYLAERO2 (152) & $K$ & XYLAERO2 $\leftrightarrow$ AXYLAO2 & 0.0042 or $\mathrm{f}(\mathrm{pH})$ \\
\hline HUMAERO (243) & $K$ & HUMAERO $\leftrightarrow$ AHUMAO & 0.15 or $\mathrm{f}(\mathrm{pH})$ \\
\hline LIMAER1 (198) & $K$ & LIMAER1 $\leftrightarrow$ ALIMA1 & 0.16 \\
\hline LIMAER2 (171) & $K$ & LIMAER2 $\leftrightarrow$ ALIMA2 & 0.016 \\
\hline LIMAERO2 (171) & K & LIMAERO2 $\leftrightarrow$ ALIMAO2 & 0.016 or $\mathrm{f}(\mathrm{pH})$ \\
\hline APINAER1 (186) & $K$ & APINAER1 $\leftrightarrow$ AAPINA1 & 0.51 \\
\hline APINAER2 (171) & $K$ & APINAER $2 \leftrightarrow$ AAPINA2 & 0.012 \\
\hline APINAERO2 (171) & $K$ & APINAERO2 $\leftrightarrow$ AAPINAO2 & 0.012 or $\mathrm{f}(\mathrm{pH})$ \\
\hline APINAER3 (191) & $K$ & APINAER3 $\leftrightarrow$ AAPINA3 & 0.26 \\
\hline APINAER4 (174) & $K$ & APINAER4 $\leftrightarrow$ AAPINA4 & 0.24 \\
\hline APINAERO4 (174) & $K$ & APINAERO4 ↔ AAPINAO4 & 0.24 or $\mathrm{f}(\mathrm{pH})$ \\
\hline BPINAER1 (192) & K & BPINAER $1 \leftrightarrow$ ABPINA1 & 0.13 \\
\hline BPINAER2 (147) & $K$ & BPINAER2 $\leftrightarrow$ ABPINA2 & 0.015 \\
\hline BPINAER3 (193) & K & BPINAER3 $\leftrightarrow$ ABPINA3 & 0.58 \\
\hline BPINAER4 (152) & K & BPINAER4 $\leftrightarrow$ ABPINA4 & 0.0090 \\
\hline BPINAERO4 (152) & $K$ & BPINAERO4 ↔ ABPINAO4 & 0.0090 or $\mathrm{f}(\mathrm{pH})$ \\
\hline BPINAER5 (184) & $K$ & BPINAER5 $\leftrightarrow$ ABPINA5 & 0.049 \\
\hline TERAER1 (217) & $K$ & TERAERO1 ↔ ATERA1 & 0.24 \\
\hline TERAERO2 (186) & $K$ & TERAERO2 $\leftrightarrow$ ATERAO2 & 0.014 or $\mathrm{f}(\mathrm{pH})$ \\
\hline TPOAER1 (215) & $K$ & TPOAER1 ↔ ATPOA1 & 0.48 \\
\hline TPOAERO2 (168) & K & TPOAER2 $\leftrightarrow$ ATPOA2 & 0.013 or $\mathrm{f}(\mathrm{pH})$ \\
\hline
\end{tabular}

* the corresponding parameters for benzene and isoprene can be found in Tables 1 and $2 .{ }^{\text {a }} H$ : Henry's law equilibrium between the gas phase and an aqueous phase; $K$ : partitioning coefficient for the equilibrium between the gas phase and an organic particulate phase.

From Kroll and Seinfeld (2005):

$K_{p, \mathrm{eff}, i}=K_{p, i}\left(1+K_{o, \mathrm{eff}, i}\right)$

At experimental conditions, we assume $K_{p, \text { eff }, i}=C_{i} /(M *$ $C_{g, i}$ ), where $C_{i}$ is the particulate-phase concentration of species $i, M$ is the mass of all absorbing compounds, and $C_{g, i}$ is the gas-phase concentration of $i$, all of which are in $\mu \mathrm{g} / \mathrm{m}^{3}$ air.

$K_{p, \text { eff }, i}=C_{\text {monomer }, i} /\left(M * C_{g, i}\right)+C_{\text {high MW species }, i} /\left(M * C_{g, i}\right)$

where $C_{\text {high MW species, } i}$ is the concentration of higher MW species. At the reference conditions of the "dry" experiments, $C_{\text {high MW species, } i}=0.1 C_{\text {monomer }, i}$ (Gao et al., 2004); therefore, $K_{p, \text { eff }, i}=1.1 C_{\text {monomer }, i} / M / C_{g, i}=1.1 K_{p, i}$. Applying Eq. (9) at reference conditions and combining Eqs. (7-9) give:

$K_{p, \text { eff }, i}=K_{p, i} \cdot\left[1+K_{o, \text { eff }, i, \text { ref }} \cdot\left(\frac{C_{\mathrm{H}+}}{C_{\mathrm{H}+, \mathrm{ref}}}\right)^{z}\right]$, where $K_{o, \text { eff }, i, \text { ref }}=0.1$. Under conditions that promote the formation of oligomers, $\mathrm{pH}$ will affect $K_{p, \text { eff }, i}$ via its effects on $K_{o, \text { eff }, i}$. An analogous formulation is applied to the effective Henry's law constants for simple carbonyls (e.g., GLY) that undergo oligomerization.

\subsubsection{Oligomer-forming surrogate SOA species}

Among the SOA mixture, we assume that species containing aldehyde groups are the main candidates for oligomer reactions. Therefore, for each surrogate condensing species (Odum et al., 1997 and Griffin et al., 1999), the fraction of compounds containing aldehyde groups, hence subject to oligomerization, is determined. Identified SOA and condensable products for all precursor species were compiled from the literature, including experimental and modeling studies (Pun and Seigneur, 2005; Pun et al., 2006 and references therein, including Yu et al., 1999; Glasius et al., 2000; Larsen et al., 2001; Jaoui and Kamens, 2001, 2003; Griffin et al., 2002). The condensable products were grouped into species that contain aldehyde groups (subject to oligomerization) and 
Table 5. Test cases for benzene, isoprene, and $\alpha$-pinene. Nominal environmental conditions are: $\mathrm{T}=298 \mathrm{~K} ; \mathrm{RH}=0.5$, $\mathrm{pH}=6$; $\mathrm{LWC}=10$ ( $\alpha$-pinene case) or $50 \mu \mathrm{g} / \mathrm{m}^{3}$ (benzene and isoprene cases); POC $=5 \mu \mathrm{g} / \mathrm{m}^{3}$.

\begin{tabular}{|c|c|c|c|}
\hline Case & Benzene & Isoprene & $\alpha$-pinene \\
\hline $\begin{array}{l}\mathrm{T} \\
\mathrm{RH} \\
\mathrm{POC} \\
\text { LWC } \\
\text { Amount of precursor reacted } \\
\text { Condensable product amount }\left(\mu \mathrm{g} / \mathrm{m}^{3}\right)\end{array}$ & $\begin{array}{l}298 \mathrm{~K} \\
0.5 \\
5 \mu \mathrm{g} / \mathrm{m}^{3} \\
50 \mu \mathrm{g} / \mathrm{m}^{3} \\
10 \mathrm{ppb}\left(31.9 \mu \mathrm{g} / \mathrm{m}^{3}\right) \\
\text { glyoxal }=4.98 \\
\text { ROPAER }=34.2 \\
\text { PHENAER } 1=0.66 \\
\text { PHENAER } 2=1.23\end{array}$ & $\begin{array}{l}298 \mathrm{~K} \\
0.5 \\
5 \mu \mathrm{g} / \mathrm{m}^{3} \\
50 \mu \mathrm{g} / \mathrm{m}^{3} \\
10 \mathrm{ppb}\left(27.8 \mu \mathrm{g} / \mathrm{m}^{3}\right) \\
\text { ISOAER } 1=6.59 \\
\text { ISOAER } 2=0.8 \\
\text { HYACET }=2.92 \\
\text { GLYALD }=5.50 \\
\text { MGLY }=3.37\end{array}$ & $\begin{array}{l}298 \mathrm{~K} \\
0.5 \\
5 \mu \mathrm{g} / \mathrm{m}^{3} \\
10 \mu \mathrm{g} / \mathrm{m}^{3} \\
5 \mathrm{ppb}\left(27.8 \mu \mathrm{g} / \mathrm{m}^{3}\right) \\
\text { APINAER } 1=1.07 \\
\text { APINAER } 2=2.13 \\
\text { APINAERO } 2=6.96\end{array}$ \\
\hline Sensitivities investigated & 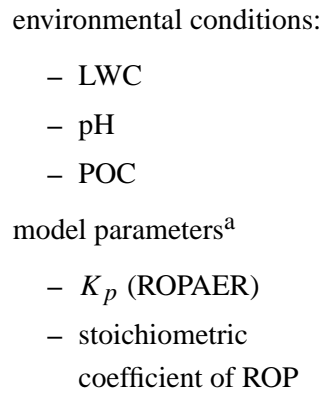 & $\begin{array}{l}\text { environmental conditions } \\
\text { - RH } \\
\text { - LWC } \\
\text { - POC } \\
\text { model parameters }{ }^{\mathrm{a}} \\
\text { - APR } \\
\text { alternative Raoult's law for- } \\
\text { mulation that excludes water }\end{array}$ & $\begin{array}{l}\text { environmental conditions } \\
\qquad \begin{array}{l}\text { - } \mathrm{pH} \\
\text { model parameters }{ }^{\mathrm{a}} \\
\text { - fraction of SOA subject } \\
\quad \text { to oligomerization } \\
-K_{O, \text { eff,ref }} \\
-C_{\mathrm{H}+\text {,ref }} \\
-z\end{array}\end{array}$ \\
\hline
\end{tabular}

a Explanation of model parameters: $K_{p}=$ empirical or estimated absorptive partitioning constant; APR = measured ambient partitioning ratio; $K_{O \text {, eff,ref }}=$ effective oligomerization equilibrium constant at reference $\mathrm{pH} ; C_{\mathrm{H}+\text {,ref }}=$ reference proton concentrations $(\mathrm{pH})$ at which

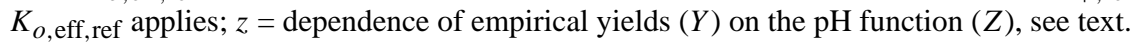

monomer species that contain no aldehyde groups. Based on the total (gas and particle yields) of each identified condensable product documented in the literature, a fraction of the condensable surrogate species, those containing the aldehyde functionality, was determined to be subject to oligomerization for each precursor species. Table 3 lists the precursors and reactions forming SOA species. The list of precursor species was selected based on available partitioning data from environmental chambers (Odum et al., 1997 and Griffin et al., 1999) and pruned based on similarity in chemical structure and reaction characteristics and the abundance of biogenic emissions of specific terpene compounds (Pun et al., 2004). MWs of actual SOA were used to convert the mass-based $\alpha$ (Odum et al., 1997 and Griffin et al., 1999) to mole-based stoichiometric coefficients. In Table 3, species subject to oligomerization are notated with an AERO suffix instead of an AER suffix, which is used for surrogate SOA not subject to oligomerization.

When oligomerization is activated, the $K_{p}$ value for the aldehyde fraction would increase, whereas the $K_{p}$ value for the fraction not subject to oligomerization would remain the same. The net effect of oligomerization is to increase the partitioning of relatively volatile SOA into the particulate phase. Table 4 lists the subsequent equilibria of surrogate
SOA species that lead to additional SOA formation via partitioning of first oxidation products toward more soluble or less volatile compounds.

\subsubsection{SOA enhancements due to oligomerization}

The overall effect of oligomerization depends on the fraction of SOA with aldehyde functional groups as well as the partition characteristics of the SOA without oligomer formation at the given conditions (e.g., total mass of the absorbing medium, total amount of condensable material, temperature). At conditions favoring the partition of the monomers to the particulate phase, e.g., low temperature, high total absorbing medium mass, high SOA concentrations, the effect of oligomerization is expected to be small, and vice versa. For example, this algorithm is applied to the $\alpha$-pinene $+\mathrm{O}_{3}$ experiments of Griffin et al. (1999) from which the partitioning parameters (stoichiometric coefficients and partitioning constants) for the original model are obtained. The relative yield difference (RYD) due to oligomerization is defined as $\left(Y_{o}-Y\right) / Y$, where $Y$ is the standard (i.e., without oligomerization) yield (mass SOA/mass reacted VOC) and $Y_{O}$ is the yield with oligomerization. The RYD depends on the total reacted VOC and ranges from 0.5 to 0.05 for VOC ranging from 17 to $65 \mathrm{ppb}$ (Griffin et al., 1999). The range of RYD values is 
in good agreement with Gao et al. (2004). Gao et al. (2004) reported RYD to range from 0.4 to 0.05 for SOA yields on seed particles with or without the addition of sulfuric acid. The decreasing RYD trend with increasing precursor concentrations is properly reproduced. Gao et al. (2004) performed two experiments using ammonium sulfate seed, one of which is comparable in concentration with two experiments in Griffin et al. (1999), which also used ammonium sulfate seed. For those experiments, the model predicts an RYD of 5-6\%, which is in good agreement with the observed RYD (5\%) from Gao et al.

Except under conditions that are less favorable to the partition into the particulate phase (e.g., due to low pre-existing organic absorbing medium mass), the effect of oligomerization is relatively small for monomer products that have low vapor pressure (e.g., humulene and $\alpha$-pinene $+\mathrm{O}_{3}$ products) because the monomers already reside in the particulate phase. Oligomerization has little effect on the formation of SOA from $\beta$-pinene, because only a small fraction of $\beta$ pinene products contains aldehyde groups based on available product information. Oligomerization enhances SOA formation from precursors (e.g., $\alpha$-pinene $+\mathrm{OH}$; terpineol, terpinene) with large fractions of products subject to oligomerization, especially for relatively volatile monomers. SOA yields are also enhanced for aromatics because of oligomerization of glyoxal.

\section{Sensitivity tests}

The sensitivity tests are designed to understand the effects of changes in environmental variables on SOA formation as well as to elucidate the effects of uncertainties in model formulation and parameters on the model predictions. Test cases focus on the new precursors and processes (see Table 5), although conclusions regarding environmental conditions can be generalized to other condensing species with similar characteristics. We consider three SOA precursors in these sensitivity tests: benzene, isoprene and $\alpha$-pinene.

\subsection{Benzene}

According to our model, four products of benzene oxidation are available for partitioning. Their total concentrations are listed in Table 5 for the reaction of $10 \mathrm{ppb}$ of benzene. The sensitivity to environmental conditions is tested first; we investigate the yields of particulate-phase organic compounds as a function of $\mathrm{LWC}, \mathrm{pH}$, and primary organic compound (POC) concentration. Second, we investigate the sensitivity of SOA yields to some model parameters.

Figure 1 shows the yield of SOA as a function of LWC, $\mathrm{pH}$, and POC. The top panel of Fig. 1 shows that the SOA yield is very sensitive to the LWC, with a very low yield of $2.5 \%$ when particles are quite dry to $43 \%$ when the LWC is $100 \mu \mathrm{g} / \mathrm{m}^{3}$ at $\mathrm{pH}$ of 4 . (Typical LWC of the ambient parti-
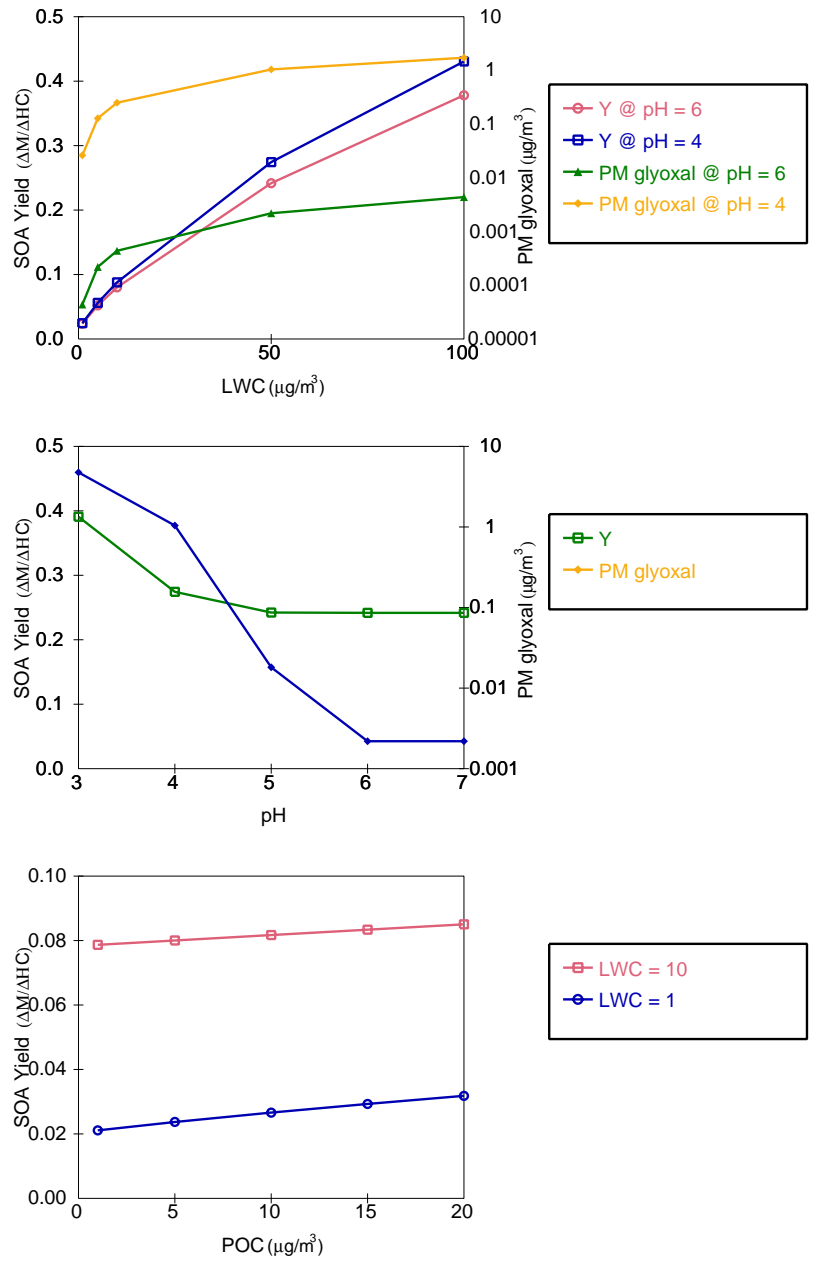

$\rightarrow \mathrm{LWC}=10$

$\rightarrow-L W C=1$

Fig. 1. Benzene SOA yield $(Y)$ as a function of liquid water content (LWC) at $\mathrm{pH}=4$ and 6 and $\mathrm{POC}=5 \mu \mathrm{g} / \mathrm{m}^{3}$ (top), as a function of $\mathrm{pH}$ at $\mathrm{LWC}=50 \mu \mathrm{g} / \mathrm{m}^{3}$ and $\mathrm{POC}=5 \mu \mathrm{g} / \mathrm{m}^{3}$ (middle), and as a function of $\mathrm{POC}$ at $\mathrm{LWC}=1$ and $10 \mu \mathrm{g} / \mathrm{m}^{3}, \mathrm{pH}=6$ (bottom).

cles ranges from $\sim 0$ to $400 \mu \mathrm{g} / \mathrm{m}^{3}$; typical $\mathrm{pH}$ ranges from -1 to 6 (Jacobson, 1999; Zhang et al., 1999; Finlayson-Pitts and Pitts, 2000)). The enhancement of SOA yield is due to several effects. First, when LWC increases, the absorbing mass (M) increases for species partitioning by Raoult's law and the solvent mass increases for compounds partitioning according to Henry's law. For the Raoult's law species, since $C_{i} / C_{g, i}=K_{p} \cdot M$, more of the available condensable compound mass enters the particulate phase. For species partitioning according to Henry's law, the dependence is also straightforward, since $C_{i} / C_{g, i}=H$.LWC. Second, because the reference $K_{p}$ values from Odum et al. (1997) and Griffin et al. (1999) were measured at dry conditions, they were corrected for the average MW for wet conditions based on Pankow (1994). Water lowers the MW of an organic mixture, thereby increasing the $K_{p}$ values. Third, oligomerization can take place in an aqueous medium, further increasing the $K_{p}$ values based on Eq. (9). 

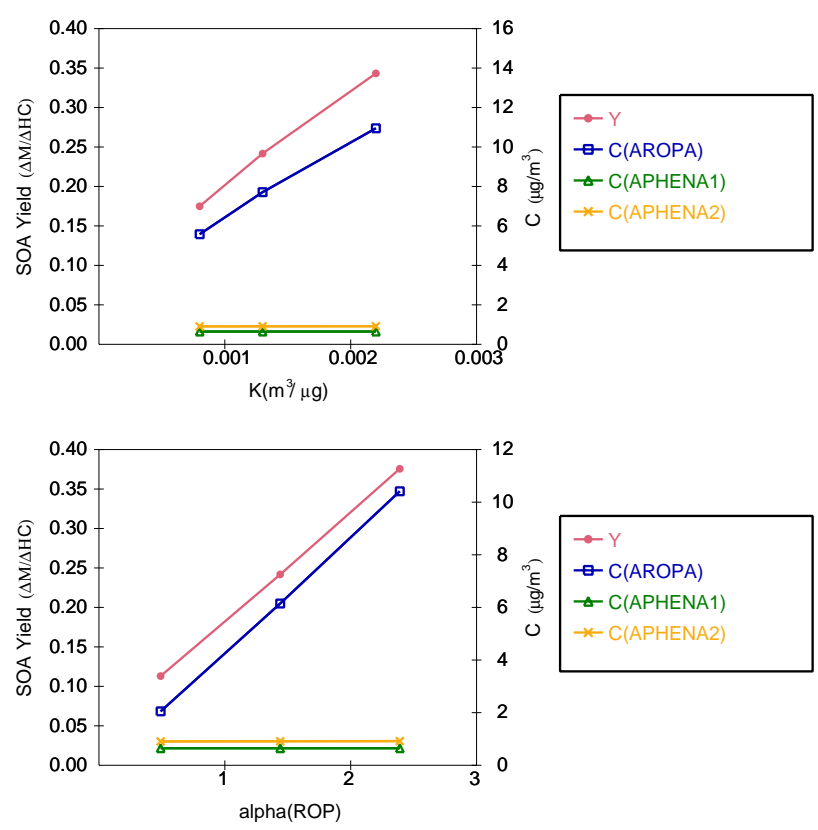

Fig. 2. Benzene SOA yield $(Y)$ as a function of $K_{p}$ of the benzene ring opening product (top) and as a function of the stoichiometric coefficient of the benzene ring opening product (bottom) at $\mathrm{LWC}=50 \mu \mathrm{g} / \mathrm{m}^{3}$ and $\mathrm{pH}=6$.

A comparison of the results from $\mathrm{pH}=4$ and $\mathrm{pH}=6$ illustrates several effects of water on the partitioning properties of SOA. At $\mathrm{pH}=6$, oligomerization of glyoxal is assumed to be at a minimum value of $10 \%$, as discussed above. The SOA yield at low LWC is similar at $\mathrm{pH}=6(2.4 \%)$ and $\mathrm{pH}=4(2.5 \%)$ because there is not sufficient monomer mass in the particulate phase available for oligomerization. At $100 \mu \mathrm{g} / \mathrm{m}^{3} \mathrm{LWC}$, the enhancement of SOA production is smaller at $\mathrm{pH}=6,38 \%$, compared to $43 \%$ at $\mathrm{pH} 4$. The case with $\mathrm{pH}=6$ represents the effects of water on the partition of monomers. At $\mathrm{LWC}=1 \mu \mathrm{g} / \mathrm{m}^{3}$, the composition of benzene SOA is $27 \%$ AROPA, 62\% APHENA1, and $11 \%$ APHENA2. The partitioning at low LWC can be explained in terms of the partitioning coefficients and the total concentrations of the species, with PHENAER1 having the highest $K_{p}$ and the largest ratio of $C_{i} / C_{g}$, followed by PHENAER2 and ROPAER. With an aerosol containing $0.76 \mu \mathrm{g} / \mathrm{m}^{3} \mathrm{SOA}$, $5 \mu \mathrm{g} / \mathrm{m}^{3}$ POC, and $1 \mu \mathrm{g} / \mathrm{m}^{3} \mathrm{LWC}$, the average MW was 84. Therefore, the $K_{p}$ values (which are $0.16,0.0057$ and $0.0013 \mathrm{~m}^{3} / \mu \mathrm{g}$ for pure organic aerosols) are $0.37,0.01$, and $0.0009 \mathrm{~m}^{3} / \mu \mathrm{g}$, respectively, for PHENAER 1 , PHENAER2, and ROPAER after correcting for MW of the absorbing medium. Despite the low $K_{p}$ value of ROPAER, AROPA accounts for a larger percentage of the SOA than APHENA2 due to its total (gas + particulate) concentration, which is higher by a factor of 30 (see Table 5).

In comparison, when $\mathrm{LWC}=100 \mu \mathrm{g} / \mathrm{m}^{3}$ (and $\mathrm{pH}=6$ ) the composition of the benzene SOA is 86\% AROPA, 5\%
APHENA1, and 9\% APHENA2. At high LWC, a large percentage of the available condensables enters the particulate phase for all three partitioning compounds; therefore, the relative abundance is related to the total amount available for partitioning. With a particle that is mostly water, the average MW is 21.3. Therefore, $K_{p}$ values corrected for MW are much larger than in the $\mathrm{LWC}=1 \mu \mathrm{g} / \mathrm{m}^{3}$ case (1.6, 0.04, and $0.004 \mathrm{~m}^{3} / \mu \mathrm{g}$, respectively, for PHENAER1, PHENAER2, and ROPAER). The mass of the particulate phase is $117 \mu \mathrm{g} / \mathrm{m}^{3}$ (including an SOA concentration of $12 \mu \mathrm{g} / \mathrm{m}^{3}$ ).

The partitioning of glyoxal is not significant when $\mathrm{pH}=6$, even though the partitioning of glyoxal increased by 2 orders of magnitude (to $0.004 \mu \mathrm{g} / \mathrm{m}^{3}$, or $0.1 \%$ of the total available glyoxal) when LWC increases from 1 to $100 \mu \mathrm{g} / \mathrm{m}^{3}$. This is because the Henry's law constant is $3.6 \times 10^{5} \mathrm{M} / \mathrm{atm}$, which converts to $9 \times 10^{-6} \mathrm{~m}^{3} / \mu \mathrm{g}$. Even at $100 \mu \mathrm{g} / \mathrm{m}^{3} \mathrm{LWC}$, particle concentrations are low because $C_{i} / C_{i, g}=9 \times 10^{-4}$. However, at $\mathrm{pH}=4$, the partition is enhanced due to the formation of high MW products from glyoxal. As shown in the middle panel of Fig. 1, at a constant LWC content of $50 \mu \mathrm{g} / \mathrm{m}^{3}$, SOA yields increase from 0.24 to 0.39 with decreasing $\mathrm{pH}$, because particulate phase glyoxal increases from $0.002 \mu \mathrm{g} / \mathrm{m}^{3}$ at $\mathrm{pH}=6$ or above (no oligomerization) to $4.8 \mu \mathrm{g} / \mathrm{m}^{3}$ at $\mathrm{pH}=3$. The sensitivity of the SOA predictions to the formulation of the oligomerization module is discussed further under the $\alpha$ pinene case.

Because of the overwhelming proportion of water, changing the POC concentration has a limited effect on the partition of SOA. The bottom panel of Fig. 1 shows cases with relatively low amount of LWC ( 1 and $\left.10 \mu \mathrm{g} / \mathrm{m}^{3}\right)$. Varying POC from 1 to $20 \mu \mathrm{g} / \mathrm{m}^{3}$ increases the SOA yield in both cases. The effect is much more pronounced when $\mathrm{LWC}=1 \mu \mathrm{g} / \mathrm{m}^{3}$. The SOA yield changes from 0.021 to 0.032 due to increased partitioning of PHENAER1, PHENAER2 and ROPAER. When LWC $=10 \mu \mathrm{g} / \mathrm{m}^{3}$, increasing POC mass from 1 to $20 \mu \mathrm{g} / \mathrm{m}^{3}$ leads to a corresponding change in SOA yield from 0.079 to 0.085 . At lower LWC, POC constitutes a larger fraction of the absorbing medium and increasing POC increases the total mass available by a greater percentage than when water constitutes more of the absorbing medium.

Due to incomplete information regarding the reaction of benzene, a parameterization is used to model SOA formation processes. We investigate now the effect on SOA yields of the parametric uncertainties of the partitioning constant $K_{p}$ of ROPAER and of the stoichiometric coefficient for ROP. Uncertainties in $K_{p}$ were determined based on the range of $K_{p}$ values $\left(0.0008-0.0022 \mathrm{~m}^{3} / \mu \mathrm{g}\right)$ deduced from different smog chamber experiments reported by Martin-Reviejo and Wirtz (2005). In a previous version of SAPRC (Carter, 1990), the stoichiometric coefficient was 0.49 instead of 1.44. Therefore, for the stoichiometric coefficient, we used this change as an uncertainty range for the lower-bound estimate and tested a full range of values from 0.49 to 2.39 centering around 1.44. The results are shown in Fig. 2. 
The top panel shows that at moderate LWC of $50 \mu \mathrm{g} / \mathrm{m}^{3}$, the total aerosol yield increases linearly with $K_{p}$, because the particle-phase concentration of ARPOA increases linearly with $K_{p}$. The partitioning of AROPA is linear with $K_{p}$ in this $K_{p}$ range because there is sufficient material in the gas phase. If the $K_{p}$ values were high, further increasing the $K_{p}$ value would result in an asymptotic increase of the AROPA yield, limited by the total mass available. Uncertainties in the $K_{p}$ value may cause the overall yield value to be uncertain by $40 \%$. The absolute uncertainty depends on the mass of SOA formed. In the $50 \mu \mathrm{g} / \mathrm{m}^{3} \mathrm{LWC}$ case, SOA changes by $2.2 \mu \mathrm{g} / \mathrm{m}^{3}$ (out of $7.7 \mu \mathrm{g} / \mathrm{m}^{3}$ ); the same uncertainty in $K_{p}$ changes SOA by only $1 \mu \mathrm{g} / \mathrm{m}^{3}$ (out of $2.6 \mu \mathrm{g} / \mathrm{m}^{3}$ ) when $\mathrm{LWC}=10 \mu \mathrm{g} / \mathrm{m}^{3}$ (not shown). Most of the mass change corresponds to a change in the AROPA mass, although small changes in APHENA1 and APHENA2 occur. Changes in APHENA1 and APHENA2 would be more pronounced if AROPA constituted a larger fraction of the absorbing medium.

The bottom panel of Fig. 2 shows the effects of changes in the stoichiometric coefficient of ROP, which affects the total condensable mass available for SOA formation. The relatively large uncertainty range (factor of about five) causes the SOA yield to cover a total range of about a factor of three (base case yield is 0.24 ), corresponding to about $4.2 \mu \mathrm{g} / \mathrm{m}^{3}$ SOA for a stoichiometric coefficient of 2.39 .

\subsection{Isoprene}

The test cases for isoprene investigate parametric uncertainties in the APR of HYACET, GLYALD, and MGLY and the formulation of the absorption module based on experimental chamber data.

The data of Matsunaga et al. (2005) that relate APR and RH show significant scatter. Therefore, we define a range of uncertainty for the APR of each species and for each RH range $(<60 \% ;>60 \%)$ using the 10th and 90th percentile of the raw APR data (Matsunaga, private communication, 2006). At RH above $60 \%$, the ranges of APR are 0.13 to $0.58,0.11$ to 0.60 , and 0.17 to 0.56 , respectively, for HYACET, GLYALD, and MGLY. At RH below $60 \%$, the ranges of APR are 0.12 to $0.36,0.06$ to 0.23 , and 0.06 to 0.37 , respectively, for HYACET, GLYALD, and MGLY. Results of the partition simulations using the lower and upper limit of those ranges are shown in Fig. 3. Total aerosol formed can increase from the base case by approximately $80 \%$ when higher APR values are used in two different RH regimes. Therefore, parametric uncertainties in APR values can cause the aerosol yield to be uncertain, with ranges of 0.03-0.13 (nominal 0.07) at low RH and 0.06-0.25 (nominal 0.14) at RH above $60 \%$.

The smog chamber experiments from which the partition parameters were deduced were conducted at low RH; therefore, the LWC content of the laboratory aerosols was low (Kroll et al., 2006). However, many of the identified prod-

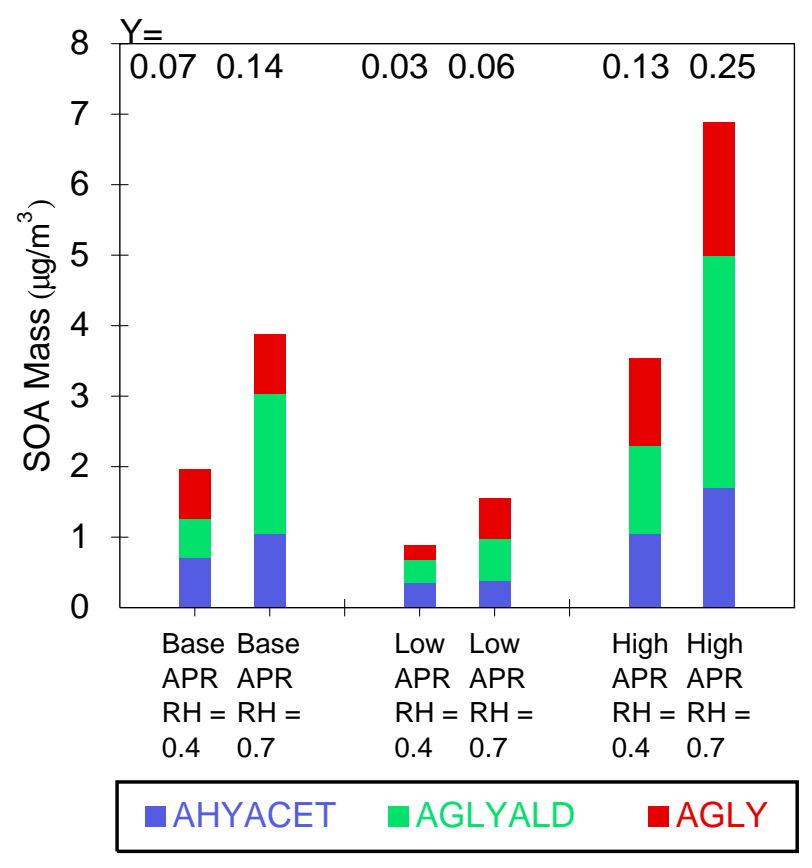

Fig. 3. Mass and yield of isoprene SOA as a function of relative humidity ( $\mathrm{RH}$ ); $\mathrm{RH}=0.4$ or 0.7 and aerosol partition ratio (APR) base case values and lower and upper end values derived from experimental data.

ucts, including polyols and peroxides (Claeys et al., 2004a, b; Edney et al., 2005; Surratt et al., 2006) are very water soluble; thus the role of water as part of the absorbing medium is inferred. In the formulation of the isoprene module based on environmental chamber data, SOA is assumed to partition into an organic phase that contains water. Doubling LWC from 50 to $100 \mu \mathrm{g} / \mathrm{m}^{3}$ increased SOA yield from 0.17 to 0.21 (Fig. 4). We attempted to investigate model formulation uncertainties by comparing with an alternative Raoult's law module in which water does not interact with organics (external mixture of organic liquid and aqueous phases). The results are shown in Fig. 4. When water is excluded from the organic absorbing medium, SOA yields drop significantly from 4.8 to $0.7 \mu \mathrm{g} / \mathrm{m}^{3}$, indicating (as suggested in the benzene test case) the sensitivity of the Raoult's law module to the mass and average MW of the absorbing medium. Even when a larger primary organic compound concentration value is used, only limited enhancement in SOA partitioning was found. Therefore, the role of water within a partitioning system can have significant effects on the aerosol yields in the ambient atmosphere.

Formulating SOA modules based on ambient vs. smog chamber data results in different predictions and sensitivities. Although the uncertainty investigation is not exhaustive, both models show overlap in the range of SOA predictions. Using nominal parameters, the absorption formulation based on Henze and Seinfeld (2006) results in higher SOA yield, but the yield is highly sensitive to the LWC. 


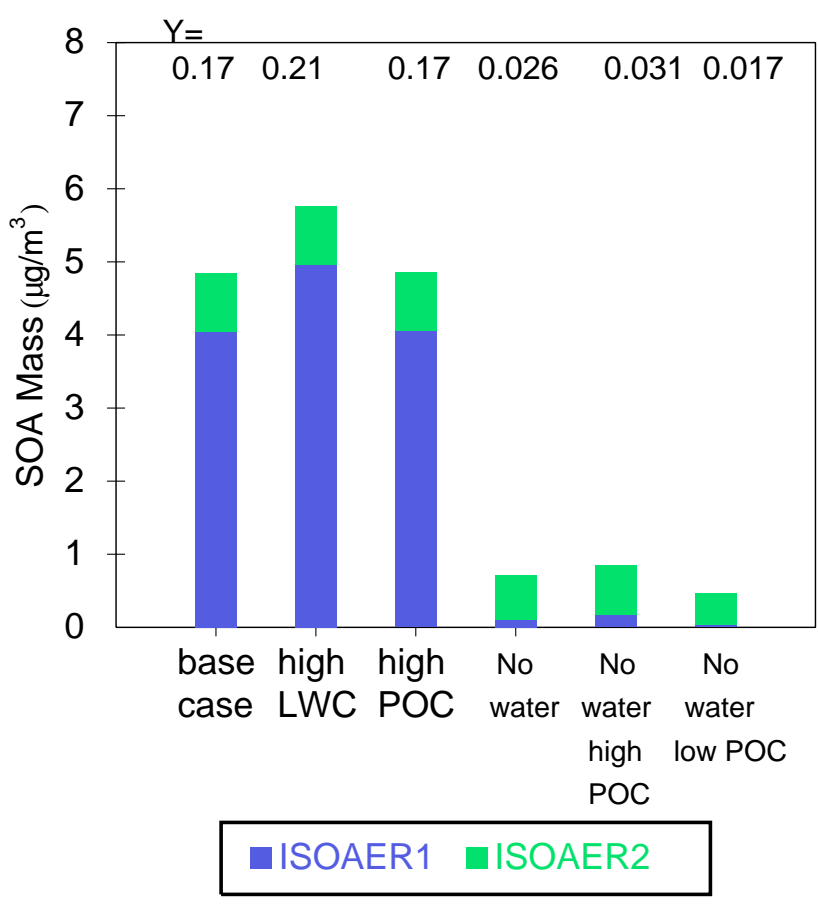

Fig. 4. Mass and yield of isoprene SOA under two scenarios where water is included or excluded as part of the absorbing medium; parameters that affect the partition of ISPRAER (LWC and POC) are varied. High LWC and high POC conditions refer to a doubling of LWC and POC concentrations, respectively, from the base case values.

The ambient formulation can predict similar or higher SOA than the absorption model if alternative APR values are used that are within the range of observed variability. Although Matsunaga et al. (2005) observed the APR to vary with $\mathrm{RH}$, it is possible that other factors contribute to the variability. The variability of parameters derived from environmental chambers cannot be fully investigated due to a more limited number of experiments.

\section{$3.3 \alpha$-pinene}

The partition of $\alpha$-pinene products (see total concentrations in Table 5) is shown in Fig. 5 as a function of $\mathrm{pH}$. The amount of SOA formed is insensitive to $\mathrm{pH}$ when $\mathrm{pH}$ is above 6 because we use this $\mathrm{pH}$ value as our reference below which oligomerization is activated. The oligomerization correction term to the partitioning constant increases with decreasing $\mathrm{pH}$, resulting in more of the product subject to oligomerization (APINAERO2) entering the particulate phase. As shown in Fig. 5, the effects of oligomerization are most pronounced at a specific $\mathrm{pH}$ range between 5 and 6 for this case study. At pH below 4, virtually all available APINAERO2 mass resides in the particulate phase and reducing $\mathrm{pH}$ further results in no further increase in the SOA mass and yield. Around $\mathrm{pH}=6$, when oligomerization is activated, the mass of oligomers increases by $6 \mu \mathrm{g} / \mathrm{m}^{3}$, while the total SOA mass increases only by $2.5 \mu \mathrm{g} / \mathrm{m}^{3}$. This is because some of the material $\left(3.9 \mu \mathrm{g} / \mathrm{m}^{3}\right)$ undergoing oligomerization is present in the particle as monomers at higher $\mathrm{pH}$. At $\mathrm{pH}=5$, APINAERO2 is already mostly present in the particulate phase as oligomers; with the effective partitioning constant increasing nine times over the monomer value.

The fraction of each SOA that is considered to be subject to oligomerization involved assuming that aldehyde is the key functional group involved. This assumption is tested by increasing that fraction to include all carbonyl species (fraction $=1$ ), thereby increasing the amount of oligomerizable compounds. The results are represented using open symbols in Fig. 5. At high $\mathrm{pH}$, when only monomers are involved in the partitioning process, the fraction of oligomerizable material is irrelevant. Increasing the oligomerizable fraction increases the potential amount of SOA and potential yield of $\mathrm{SOA}$ at low $\mathrm{pH}$. By increasing the fraction of oligomerizable material from 0.77 to 1.0 for APINAERO2, the mass concentration of AAPINA2 increases from 8.1 to $9.1 \mu \mathrm{g} / \mathrm{m}^{3}$ (100\% of the condensable material) at $\mathrm{pH}=3$. The overall SOA yield increases accordingly from 0.33 to 0.37 .

Parameters used in the formulation of the SOA module are tested to understand where key uncertainties lie. Parameters are changed in the direction that leads to less oligomerization. We tested the sensitivity to $K_{o \text {,eff, ref, }} z$, and the ref-

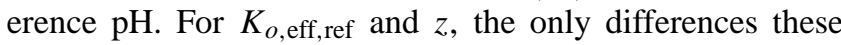
parameters make in the partitioning of the oligomer species are simulated when the effect of oligomerization is largest

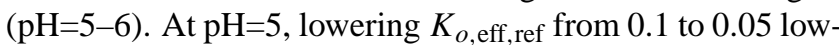
ers the enhancement factor applied to $K_{p}$ due to oligomerization from about 9 to about 5 . However, the effect on the formation of SOA is small because the equilibrium is strongly displaced toward oligomers as the $\mathrm{pH}$ decreases by only one unit. Similarly, lowering z from 1.91 to 1.5 would result in an enhancement factor of 4 to the monomer value of $K_{p}$. The maximum effect on oligomer concentrations is only a decrease of $0.6 \mu \mathrm{g} / \mathrm{m}^{3}$ (see Fig. 6).

A more important parameter seems to be the proton concentration needed to catalyze oligomerization reactions. If we assume that a lower $\mathrm{pH}$ (5 instead of 6 ) is needed before oligomerization can take place, the yield curve for oligomers is essentially shifted down one $\mathrm{pH}$ unit. Therefore, the reference $\mathrm{pH}$ value below which oligomerization becomes significant appears to be a critical parameter for an SOA model.

For this test case, once oligomerization is activated, SOA yields are not very sensitive to the parameters used in the oligomerization formulation. There is a small range of $\mathrm{pH}$ where the aerosol yield is sensitive to parameters used in oligomerization; at lower $\mathrm{pH}$, nearly $100 \%$ of the mass enters the particulate phase. For more volatile species, the uncertainty in the formulation may be more important. 


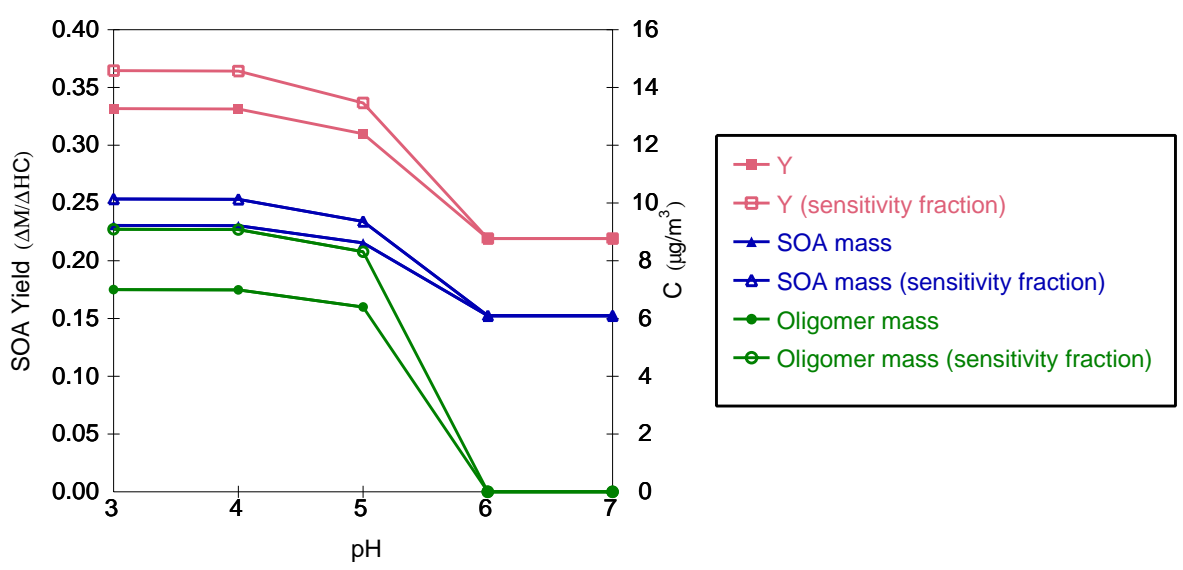

Fig. 5. Yield and concentrations of total SOA and oligomers under the base case (solid symbols) and in the sensitivity case where all APINAER2 products are assumed to undergo oligomerization ("sensitivity: fraction" denotes cases where the fraction of condensable carbonyl products that is subject to oligomerization $=1$; open symbols).

\section{Conclusions and recommendations}

The partitioning of many organic compounds is extremely sensitive to LWC because water is an abundant absorbing medium in the ambient atmosphere. Water also facilitates the partition because it has a lower MW than most partitioning compounds, effectively diluting the particle phase concentrations on a molar basis. Known oligomerization reactions take place in an organic phase that contains water and protons. However, the sensitivity to water may be overestimated if not all liquid water present in aerosols is available to interact with organic compounds. Our sensitivity study with the isoprene products shows that models including and excluding water from the partition calculation of organic species can give very different results. Furthermore, other physical processes can also affect the interaction between water and organic compounds, including phase separation (Erdakos and Pankow, 2004) or the formation of micelles (Tabazadeh, 2005) or inverted micelles (Cai and Griffin, 2003). Physical (phase) and chemical (activity coefficients) interactions between water and organics need to be further investigated to support accurate modeling, especially if multiple liquid phases are present in the ambient atmosphere. Laboratory experiments conducted at higher RH will help elucidate the role of water in partitioning. For example, SOA yield of $8-25 \%$ were reported based on dry chamber experiments (Martin-Reviejo and Wirtz, 2005). However, when water is considered as part of the organic-containing aerosol, SOA yield in the modeled atmosphere can be significantly larger. Such behavior remains to be verified. At present, measurement methods employed in the routine monitoring networks exclude the majority of the particulate water due to sample heating, further limiting the ability to analyze aqueous-organic interactions.

Due to incomplete information, uncertainties in SOA yields due to the formulation of the model and the selection

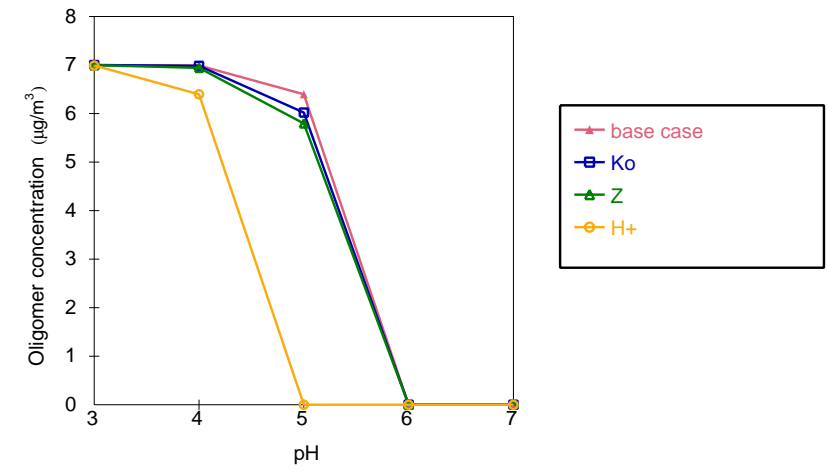

Fig. 6. Concentrations of oligomers as a function of $\mathrm{pH}$ in sensitivity cases where parameters in the calculation of the effective partition constant due to oligomerization is changed. ( $K_{O}$ denotes the case where $K_{o \text {,eff }}$, is reduced; $Z$ denotes the case where $z$ is reduced and $\mathrm{H}^{+}$denotes the case where the $\mathrm{pH}$ value required to activate oligomerization is reduced.)

of model parameters can be significant. The uncertainties in the predicted yield due to parameterization can be as much as those due to variabilities in the most influential ambient conditions. Therefore, further experimental work is needed to characterize the gas-phase and particulate-phase products of potentially significant SOA precursors such as benzene and isoprene. Such molecular identification is available for isoprene SOA in environmental chambers (Surratt et al., 2006). However, there seems to be a discrepancy between the multitude of complex SOA species found in environmental chambers and several small molecules found in abundance in ambient measurements (Matsunaga et al., 2005). The importance of laboratory-identified SOA species in the ambient atmosphere remains to be quantified. The dependence of SOA formation on co-pollutants, such as $\mathrm{NO}_{\mathrm{x}}$ and $\mathrm{SO}_{2}$, should 
also be accounted for to the extent possible. Quantitative yield information will be quite necessary for the development of models that can be used with more confidence.

Processes that can enhance the partition of aerosols by decreasing the volatility of end products need to be investigated further. Our sensitivity study shows that the effects of oligomerization can increase SOA formation by orders of magnitude at low $\mathrm{pH}$. However, many parameters are uncertain, and laboratory studies tend to be conducted under conditions that favor these processes. More experiments that use conditions relevant to the ambient atmosphere would provide valuable data to evaluate the importance of such processes. When such data become available, further theoretical development can be accomplished to support the development of more robust models.

Acknowledgements. The Coordinating Research Council provided funding for this work under Project A-59. The authors wish to thank the Coordinating Research Council (CRC) Atmospheric Impacts Committee for its support and constructive comments. Special thanks are due to M. Jang (University of North Carolina), S. Matsunaga (National Center for Atmospheric Research) and J. Kroll (California Institute of Technology; now at Aerodyne Research, Inc.) for detailed discussions of their work.

Edited by: R. Cohen

\section{References}

Aumont, B., Madronich, S., Bey, I., and Tyndall, G. S.: Contribution of Secondary VOC to the Composition of Aqueous Atmospheric Particles: A Modeling Approach, Atmos. Chem., 35, 59-75, 2000.

Barsanti, K. C. and Pankow, J. F.: Thermodynamics of the formation of atmospheric organic particulate matter by accretion reactions Part 1: aldehydes and ketones, Atmos. Environ., 38, 43714382, 2004.

Barsanti, K. C. and Pankow, J. F.: Thermodynamics of the formation of atmospheric organic particulate matter by accretion reactions Part 2: dialdehydes, methylglyoxal and diketones, Atmos. Environ., 39, 6597-6607, 2005.

Cai, X. and Griffin, R. J.: Modeling the formation of secondary organic aerosol in coastal areas: role of the sea-salt aerosol organic layer, J. Geophys. Res., 108(D15), 4440, doi:10.1029/2002JD 003053, 2003.

Carter, W. P. L.: A detailed mechanism for the gas-phase atmospheric reactions of organic compounds, Atmos. Environ., 24A, 481-518, 1990.

Carter, W. P. L. and Atkinson, R.: Development and evaluation of a detailed mechanism for the atmospheric reactions of isoprene and $\mathrm{NO}_{\mathrm{x}}$, Int. J. Chem. Kinet., 28, 497-530, 1996.

Claeys, M., Graham, B., Vas, G., Wang, W., Vermeylen, R., et al: Formation of secondary organic aerosols through photooxidation of isoprene, Science, 303, 1173-1176, 2004a.

Claeys, M., Wang, W., Ion, A. C., Kourtchev, I., Gelencsér, A., and Maenhaut, W.: Formation of secondary organic aerosols from isoprene and its gas-phase oxidation products through reac- tion with hydrogen peroxide, Atmos. Environ., 38, 4093-4098, $2004 b$.

Czoschke, N. M., Jang, M., and Kamens, R. M.: Effect of acidic seed on biogenic secondary organic aerosol growth, Atmos. Environ., 37, 4287-4299, 2003.

Docherty, K. S., Wu, W., Lim, Y. B., and Ziemann, P. J.: Contributions of organic peroxides to secondary aerosol formed from reactions of monoterpenes with $\mathrm{O}_{3}$, Environ. Sci. Technol., 39, 4049-4059, 2005.

Dommen, J., Metzger, A., Duplissy, J., Kalberer, M., Alfarrra, M. R., et al.: Laboratory observation of oligomers in the aerosol from isoprene/ $\mathrm{NO}_{\mathrm{x}}$ photooxidation, Geophys. Res. Lett., 33, L13805, doi:10.1029/2006GL026523, 2006.

Edney, E. O., Kleindienst, T. E., Jaoui, M., Lewandowski, M., Offenbery, J. H., Wang, W., and Claeys, M.: Formation of 2-methyl tetrols and 2-methylglyceric acid in a secondary organic aerosol from laboratory irradiated isoprene/ $\mathrm{NO}_{\mathrm{x}} / \mathrm{SO}_{2} /$ air mixtures and their detection in ambient PM2.5 samples collected in the eastern United States, Atmos. Environ., 39, 5281-5289, 2005.

Erdakos, G. B. and Pankow, J. F.: Gas/particle partitioning of neutral andionizing compounds to single- and multi-phase aerosol particles. 2. Phase separation in liquid particulate matter containing both polar and low-polarity organic compounds, Atmos. Environ., 38, 1005-1013, 2004.

Ervens, B., Feingold, G., Frost, G. J., and Kreidenweis, S. M.: A modeling study of aqueous production of dicarboxylic acid: chemical pathways and speciated organic mass production, J. Geophys. Res., 105(D15), 205, doi:10.1029/2003JD004387, 2004a.

Ervens, B., Feingold, G., Clegg, S. L., and Kreidenweis, S. M.: A modeling study of aqueous production of dicarboxylic acid: 2 Implications for cloud microphysics, J. Geophys. Res., 105(D15), 206, doi:10.1029/2004JD004575, 2004b.

Finlayson-Pitts, B. J. and Pitts Jr., J. N.: Chemistry of the Upper and Lower Atmosphere: Theory, Experiments, and Applications, Academic Press, San Diego, CA, 2000.

Gao, S., Keywood, M., Ng, N., Surratt, J., Varutbangkul, V., et al.: Low-molecular weight and oligomeric components in secondary organic aerosols from the ozonolysis of cycloalkenes and $\alpha$-pinene, J. Phys. Chem., 108, 10 147-10 164, 2004.

Glasius, M., Lahaniati, M., Calogirou, A., Bella, D. D., Kotzias, D., et al.: Carboxylinc acids in secondary aerosols from oxidation of cyclic monoterpenes by ozone, Environ. Sci. Technol., 34, 10011010, 2000.

Griffin, R. J., Cocker III, D. R., Flagan, R. C., and Seinfeld, J. H.: Organic aerosol formation from the oxidation of biogenic hydrocarbons, J. Geophys. Res., 104, 3555-3567, 1999.

Griffin, R., Dabdub, D., and Seinfeld, J. H.: Secondary organic aerosol. I. Atmospheric Chemical Mechanism for production of molecular constituents, J. Geophys. Res., 107(D17), 4332, doi:10.1029/2001JD00541, 2002.

Griffin, R. J., Nguyen, K., Dabdub, D., and Seinfeld, J. H.: A coupled hydrophobic-hydrophilic model for predicting secondary organic aerosol formation, J. Atmos. Chem., 44, 171-190, 2003.

Hastings, W. P., Koehler, C. A., Bailey, E. L., and De Hann, D. O.: Secondary organic aerosol formation by glyoxal hydration and oligomer formation: humidity effects and equilibrium shifts during analysis, Environ. Sci. Technol., 39, 8728-8735, 2005.

Henze, D. K. and Seinfeld, J. H.: Global secondary organic aerosol 
from isoprene oxidation, Geophys. Res. Lett., 33, L09812, doi:10.1029/2006GL025976, 2006.

Iinuma, Y., Böge, O., Gnauk, T., and Herrmann, H.: Aerosol chamber study of $\alpha$-pinene $/ \mathrm{O}_{3}$ reaction: influence of particle acidity on aerosol yields and products, Atmos. Environ., 38, 761-773, 2004.

Jacobson, M. Z.: Development and application of a new air pollution modeling system, Part II: aerosol module structure and design, Atmos. Environ., 31, 131-144, 1997.

Jacobson, M. Z.: Fundamentals of Atmospheric Modeling, Cambridge University Press, Cambridge, UK, 1999.

Jang, M. and Kamens, R. M.: Atmospheric secondary aerosol formation by heterogeneous reactions of aldehydes in the presence of a sulfuric acid catalyst, Environ. Sci. Technol., 35, 4758-4766, 2001.

Jang, M., Czoschke, N. M., Lee, S., and Kamens, R. M.: Heterogeneous atmospheric aerosol production by acid-catalyzed particlephase reactions, Science, 298, 814-817, 2002.

Jang, M., Lee, S., and Kamens, R. M.: Organic aerosol growth by acid catalyzed heterogeneous reactions of octanal in a flow reactor, Atmos. Environ., 37, 2125-2138, 2003.

Jang, M., Czoschke, N. M., and Northcross, A. L.: Semiempirical model for organic aerosol growth by acid catalyzed heterogeneous reactions of organic carbonyls, Environ. Sci. Technol., 39, 164-174, 2005.

Jang, M., Czoschke, N. M., Northcross, A. L., Cao, G., and Shaof, D.: SOA formation from partitioning and heterogeneous reactions: model study in the presence of inorganic species, Environ. Sci. Technol., 40, 3013-3022, 2006.

Jaoui, M. and Kamens, R. M.: Mass balance of gaseous and particulate products analysis from $\alpha$-pinene $+\mathrm{NO}_{\mathrm{x}}$ in the presence of natural sunlight, J. Geophys. Res., 106, 12 541-12 559, 2001.

Jaoui, M. and Kamens, R .M.: Gas and particulate products distribution from the photoxidation of $\alpha$-humulene in the presence of $\mathrm{NO}_{\mathrm{x}}$, natural atmospheric air and sunlight, J. Atmos. Chem., 46, 29-54, 2003.

Johnson, D., Jenkin, M. E., Wirtz, K., and Martin-Reviejo, M.: Simulating the formation of secondary organic aerosol from the photooxidation of aromatic hydrocarbons, Environ. Chem., 2, 3548, 2005.

Koehler, C. A., Fillo, J. D., Ries, K. A., Sanchez, J. T., and DeHann, D. O.: Formation of secondary organic aerosol by reactive condensation of furandiones, aldehydes, and water vapor onto inorganic aerosol seed particles, Environ. Sci. Technol., 38, 50645072, 2004

Kroll, J. H., Ng, N. L., Murphy, S. M., Flagan, R. C., and Seinfeld, J. H.: Secondary organic aerosol formation from isoprene photooxidation under high- $\mathrm{NO}_{\mathrm{x}}$ conditions, Geophys. Res. Lett., 32, L18808, doi:10.1029/2005GL023637, 2005a.

Kroll, J. H. and Seinfeld, J. H.: Representation of secondary organic aerosol laboratory chamber data for the interpretation of mechanisms of particle growth, Environ. Sci. Technol., 39, 4159-4165, 2005.

Kroll, J. H., Ng, N. L., Murphy, S. M., Varubangkul, V., Flagan, R. C., and Seinfeld, J. H.: Chamber studies of secondary organic aerosol growth by reactive uptake of simple carbonyl compounds, J. Geophys. Res., 110, D23207, doi:10.1029/2005JD006004, 2005b.

Kroll, J. H., Ng, N. L., Murphy, S. M., Flagan, R. C., and Sein- feld, J. H.: Secondary organic aerosol formation from isoprene photooxidation, Environ. Sci. Technol., 40, 1869-1877, 2006.

Larsen, B. R., Bella, D. D., Glasius, M., Winterhalter, R., Jensen, N. R., Hjorth, J.: Gas-phase OH oxidation of monoterpenes: gaseous and particulate products, J. Atmos. Chem., 38, 231-276, 2001.

Liggio, J., Li, S. M., and McLaren, R.: Heterogeneous Reactions of glyoxal on particulate matter: identification of acetals and sulfate esters, Environ. Sci. Technol., 39, 1532-1541, 2005.

Lim, H.-J., Carlton, A. C., and Turpin, B. J.: Isoprene forms secondary organic aerosol through cloud processing: model simulations, Environ. Sci. Technol., 39, 4441-4446, 2005.

Limbeck, A., Kulmala, M., and Puxbaum, H.: Secondary organic aerosol formation via heterogeneous reaction of gaseous isoprene on acidic particles, Geophys. Res. Lett., 30(19), 1996, doi:10.1029/2003GL017738, 2003.

Matsunaga, S. N., Wiedinmyer, C., Guenther, A. B., Oriando, J. J., Karl, T., Toohey, D. W., Greenberg, J. P., and Kajii, Y.: Isoprene oxidation products are a significant atmospheric aerosol component, Atmos. Chem. Phys. Discuss., 5, 11 143-11 156, 2005.

Martin-Reviejo, M. and Wirtz, K.: Is benzene a precursor for secondary organic aerosol?, Environ. Sci. Technol., 39, 1045-1054, 2005.

Meng, Z. and Seinfeld, J. H.: On the source of the submicron droplet mode of urban and regional aerosols, Aerosol Sci. Technol., 20, 253-265, 1994.

Morris, R. E., Koo, B., Guenther, A., Yarwood, G., McNally, D., Tesche, T. W., Tonnesen, G., Boylan, J., and Brewer, P.: Model sensitivity evaluation for organic carbon using two multipollutant air quality models that simulate regional haze in the southeastern United States, Atmos. Environ., 40, 4960-4972, 2006.

Odum, J. R., Jungkamp, T. P. W., Griffin, R. J., Forstner, H. J. L., Flagan, R. C., and Seinfeld, J. H.: Aromatics, reformulated gasoline, and atmospheric organic aerosol formation, Environ. Sci. Technol., 31, 1890-1897, 1997.

Pankow, J. F.: An absorption model of the gas/aerosol partitioning involved in the formation of secondary organic aerosol, Atmos. Environ., 28, 189-193, 1994.

Pun, B. K., Griffin, R. J., Seigneur, C., and Seinfeld, J. H.: Secondary organic aerosol: II. comprehensive thermodynamic module for gas/particle partitioning of molecular constituents, J. Geophys. Res., 107(D17), 4333, doi:2001D000542, 2002.

Pun, B. K., Wu, S.-Y., Seigneur, C., Seinfeld, J. H., Griffin, R. J., and Pandis, S. N.: Uncertainties in modeling secondary organic aerosols: Three-dimensional modeling studies in Nashville/Western Tennessee, Environ. Sci. Technol., 37, 3647 3661, 2003.

Pun, B. K., Seigneur, C., and Knipping, E.: Optimizing secondary organic aerosol representation in particulate matter air quality models, Air \& Waste Management Association Visibility Specialty Conference - Regional and Global Perspectives on Haze: Causes, Consequences and Controversies, 26-29 October 2004, Asheville, North Carolina, 2004.

Pun, B. K. and Seigneur, C.: Secondary organic aerosols: A literature review, Project A-59, Coordinating Research Council, Alpharetta, GA, http://www.crcao.org, 2005.

Pun, B. K., Seigneur, C., Pankow, J., Chang, E., Griffin, R., and Knipping, E.: An upgraded absorptive secondary organic aerosol 
partitioning module for three-dimensional air quality applications, American Association of Aerosol Research Conference, October 2005, Austin, TX, 2005.

Pun, B., Seigneur, C., and Lohman, K.: Modeling secondary organic aerosol via multiphase partitioning with molecular data, Environ. Sci. Technol., 40, 4722-4731.

Saxena, P. and Seigneur, C.: On the oxidation of $\mathrm{SO}_{2}$ to sulfate in atmospheric aerosols, Atmos. Environ., 21, 807-812, 1987.

Seigneur, C. and Moran., M.: Chapter 8: Chemical transport models, in: Particulate Matter Science for Policy Makers: A NARSTO Assessment, edited by: McMurry, P. H., Shepherd, M., and Vickery, J., Cambridge University Press, Cambridge, United Kingdom, pp. 283-323, 2004.

Strader, R., Lurmann, F., and Pandis, S. N.: Evaluation of secondary organic aerosol formation in winter, Atmos. Environ., 39, 48494864, 1999.

Surratt, J. D., Murphy, S. M., Kroll, J. H., Ng, N. L., Hilderbrandt, L., Sorooshian, A., Szmigielski, R., Vermeylen, R., Maenhaut, W., Claeys, M., Flagan, R., and Seinfeld, J. H.: Chemical composition of secondary organic aerosol formed from the photooxidation of isoprene, J. Phys. Chem. A., 110(31), 9665-9690, doi:10.1021/jp061734m, 2006.

Tabazadeh, A.: Organic aggregate formation in aerosols and its impact on the physicochemical properties of atmospheric particles, Atmos. Environ., 39, 5472-5480, 2005.
Warneck, P.: In-cloud chemistry opens pathway to the formation of oxalic acid in the marine atmosphere, Atmos. Environ., 37, 2423-2427, 2003.

Yu, J., Flagan R. C., and Seinfeld, J. H.: Identification of products containing $-\mathrm{COOH},-\mathrm{OH}$ and $-\mathrm{C}=\mathrm{O}$ in atmospheric oxidation of hydrocarbons, Environ. Sci. Technol., 32, 2357-2370, 1998.

Zhang, Y., Seigneur, C., Seinfeld, J. H., Jacobson, M., Clegg, S., Binkowski, F. S.: A comparative review of inorganic aerosol thermodynamic equilibrium modules: similarities, differences, and their likely causes, Atmos. Environ., 34, 117-137, 1999.

Zhang, Y., Pun, B., Vijayaraghavan, K., Wu, S.-Y., Seigneur, C., Pandis, S., Jacobson, M., Nenes A., and Seinfeld, J.H.: Development and application of the Model of Aerosol Dynamics, Reaction, Ionization and Dissolution, J. Geophys. Res., 109, D01202, doi:10.1029/2003JD003501, 2004.

Zhao, J., Levitt, N. P., Zhang, R., Chen, J.: Heterogeneous reactions of methylglyoxal in acidic media: implications for secondary organic aerosol formation, Environ. Sci. Technol., 40, 7682-7687, 2006.

Ziemann, P. J.: Aerosol products, mechanisms, and kinetics of heterogeneous reactions of ozone with oleic acid in pure and mixed particles, Faraday Discuss., 130, 469-490, 2005. 